\title{
Evaluation of the contribution of tropical cyclone seeds to changes in tropical cyclone frequency due to global warming in high-resolution multi-model ensemble simulations
}

\author{
Yohei Yamada ${ }^{1 *}$ (D), Chihiro Kodama ${ }^{1}$, Masaki Satoh², Masato Sugi ${ }^{3}$, Malcolm J. Roberts $^{4}$, Ryo Mizuta ${ }^{3}$, \\ Akira T. Noda ${ }^{1}$, Tomoe Nasuno ${ }^{1}$, Masuo Nakano ${ }^{1}$ and Pier Luigi Vidale ${ }^{5}$
}

\begin{abstract}
Previous projections of the frequency of tropical cyclone genesis due to global warming, even in terms of sign of the change, depends on the chosen model simulation. Here, we systematically examine projected changes in tropical cyclones using six global atmospheric models with medium-to-high horizontal resolutions included in the sixth phase of the Coupled Model Intercomparison Project/High-Resolution Model Intercomparison Project. Changes in the frequency of tropical cyclone genesis could be broken down into the contributions from (i) the tropical cyclone seed, a depression having a closed contour of sea level pressure with a warm core and (ii) the survival rate, the ratio of the frequency of tropical cyclone genesis to that of tropical cyclone seeds. The multimodel ensemble mean indicates that tropical cyclone genesis frequencies are significantly decreased during the period 1990-2049, which is attributable to changes in tropical cyclone seeds. Analysis of the individual models shows that although most models project a more or less decreasing trend in tropical cyclone genesis frequencies and seeds, the survival rate also contributes to the result in some models. The present study indicates the usefulness of decomposition into the frequency of the tropical cyclone seeds and the survival rate to understand the cause of uncertainty in projected frequencies of tropical cyclone genesis.
\end{abstract}

Keywords: Global warming, Tropical cyclone, Tropical cyclone seed, Survival rate, High-Resolution Model Intercomparison Project

\section{Introduction}

Many previous studies have examined changes in tropical cyclone (TC) activity, such as TC genesis frequency, TC intensity, and precipitation associated with TCs, due to global warming; these have been summarized by Knutson et al. (2010, 2019, 2020). However, the topic is still controversial. Focusing on TC genesis frequency,

\footnotetext{
* Correspondence: yoheiy@jamstec.go.jp

'Japan Agency for Marine-Earth Science and Technology, 3173-25

Showa-machi, Yokohama, Kanagawa 236-0001, Japan

Full list of author information is available at the end of the article
}

most high-resolution atmospheric general circulation models project a decrease in the frequency of the global TC genesis due to global warming (Murakami et al. 2012, 2014; Oouchi et al. 2006; Roberts et al. 2015; Satoh et al. 2015; Sugi et al. 2009, 2017; Sugi and Yoshimura 2012; Wehner et al. 2015; Yamada et al. 2010, 2017; Yamada and Satoh 2013; Yoshida et al. 2017; Zhao et al. 2009). However, Bhatia et al. (2018) showed an increase in TC genesis frequency using a high-resolution atmosphere-ocean coupled general circulation model. Understanding the reasons for these discrepancies is necessary 
in order to gain reliable future projections of $\mathrm{TC}$ frequency.

Recently, some studies have noted the response of TC seeds (incipient vortices of TCs) to global warming and its relation to TC genesis frequency (Lee et al. 2020; Sugi et al. 2020; Vecchi et al. 2019). Vecchi et al. (2019) investigated the reasons for the increase in $\mathrm{TC}$ genesis under the warmer climate conditions projected by Bhatia et al. (2018). Using the same model as Bhatia et al. (2018), i.e., with nudged sea surface temperature (SST) experiments and three horizontal resolutions $(\sim 200 \mathrm{~km}, \sim 50 \mathrm{~km}$, and $\sim 25 \mathrm{~km}$ ), they showed that global TC frequency responds to both an increase in TC seeds due to warming and the less efficient development of these seeds into TCs (survival rate; SR). In addition, the highest resolution model $(\sim 25 \mathrm{~km})$ projected a more significant increase in TC seeds than the lower-resolution models. Sugi et al. (2020) examined future change in TC seed frequency using two high-resolution models: the $20-\mathrm{km}$ mesh of the Meteorological Research Institute/Japan Meteorological Agency Atmospheric General Circulation Model (MRI-AGCM3; Mizuta et al. 2012; Murakami et al. 2012) and the 14- $\mathrm{km}$ mesh of the Nonhydrostatic ICosahedral Atmospheric Model (NICAM; Satoh et al. 2008, 2014; Tomita and Satoh 2004; Kodama et al. 2015). Contrary to Vecchi et al. (2019), they showed a clear reduction in TC seed frequency, which contributes to a decrease in the relatively weak TC frequency. Although changes in $\mathrm{TC}$ and $\mathrm{TC}$ seed frequencies showed opposite signs between Vecchi et al. (2019) and Sugi et al. (2020), both studies indicated that changes in TC seed frequency under warmer climates possibly influence changes in TC frequency. This discrepancy may be a result of the differing models, definitions of TC seeds, and/or experimental designs between the two studies. Variability in the response of TC seed frequency due to global warming provides potential clues as to discrepancies in future TC frequency projections among (i) models and (ii) horizontal resolutions, helping to reduce uncertainties.

In order to evaluate differences in the response of TC seed frequency and its relation to TC frequency across different models and horizontal resolutions, it is necessary to examine the response of TC seed frequency to global warming by utilizing the outputs of models with a common setting and a specific definition of TC seed. Haarsma et al. (2016) proposed the High-Resolution Model Intercomparison Project (HighResMIP) under the sixth phase of the Coupled Model Intercomparison Project (CMIP6; Eyring et al. 2016). Eighteen models with more than two types of horizontal resolution were included in HighResMIP (see Table A1 of Haarsma et al. 2016). Camargo (2013) examined TC activity using the CMIP5 dataset, showing that although resolution is not the only contributor that determines model TC activity, the models with the highest horizontal resolution reproduced the highest levels of global TC activity. Using HighResMIP models, Roberts et al. (2019b) showed (i) increases in TC frequency and seasonal accumulated cyclone energy and (ii) improvement in the representation of TC intensity and TC track with finer resolution models. These findings indicate the advantage of HighResMIP for use in TC studies.

Using the HighResMIP dataset, we can examine the differences in the response of TC seed frequency and SR between models under a common experimental protocol. The impact of horizontal resolution can also be assessed. In addition, we can discuss the contribution of changes in TC seed frequency and SR for each model due to global warming. We used six models, which are described in Section 2. TCs and TC seeds were detected with an objective tracking algorithm named TempestExtremes (Ullrich and Zarzycki 2017; Zarzycki and Ullrich 2017). In Section 2, we briefly describe the models, the tracking algorithm, and the definitions of $\mathrm{TC}$ seed and SR that were used in this study. We examine the trends in three parameters (TC genesis frequency, TC seed frequency, and SR) in relation to (i) global warming and (ii) each other (Section 3). In Section 4, we discuss (i) the contributions of TC seeds and SR to TC frequency and (ii) the impact of horizontal resolution on TC frequency, TC seed frequency, and SR. The summary and concluding remarks are given in Section 5.

\section{Methods/experimental}

\subsection{Models and experimental design}

In the present study, we used the six models included in CMIP6 HighResMIP: Centre National de Recherches Meteorologiques and Cerfacs for CMIP6 (CNRM-CM6; Voldoire et al. 2019); EC-Earth3P (Haarsma et al. 2020); the Hadley Centre Global Environment Model 3-Global Coupled version 3.1 (HadGEM3-GC3.1; Roberts et al. 2019a); the Max Planck Institute for Meteorology Earth System Model (MPI-ESM1.2; Gutjahr et al. 2019); MRIAGCM3 (Mizuta et al. 2012); and the latest stable version of NICAM modified for CMIP6 (NICAM16-S; Kodama et al. 2020). We abbreviated them by combining the model name and horizontal grid interval. For instance, CNRM156 means CNRM-CM6 with a horizontal grid interval of $156 \mathrm{~km}$. Other abbreviations and resolutions are listed in Table 1.

Haarsma et al. (2016) described the experimental design of the HighResMIP simulation, which consisted of tier 1, 2, and 3 simulations. Tiers 1 and 3 were atmosphere only simulations, whereas tier 2 was a coupled ocean-atmosphere simulation. Vecchi et al. (2019) showed the increase in TC seed due to the rise in SST (see their Fig. 14). Therefore, it is expected that a change 
Table 1 Lists of models and horizontal grid intervals used in the present study

\begin{tabular}{llll}
\hline Model name & Horizontal grid interval at the equator & Abbreviation & Reference \\
\hline CNRM-CM6 & $156 \mathrm{~km}$ & CNRM156 & Voldoire et al. (2019) \\
EC-Earth3P & $55 \mathrm{~km}$ & CNRM055 & Haarsma et al. (2020) \\
HadGEM3-GC3.1 & $78 \mathrm{~km}$ & EC078 & Roberts et al. (2019a) \\
& $39 \mathrm{~km}$ & EC039 & GG208 \\
MPI-ESM1.2 & $208 \mathrm{~km}$ & HG093 & Gutjahr et al. (2019) \\
& $93 \mathrm{~km}$ & HG039 & Mizuta et al. (2012) \\
MRI-AGCM3 & $39 \mathrm{~km}$ & MPI100 & MPI052 \\
NICAM.16-S & $100 \mathrm{~km}$ & MRI060 & Kodama et al. (2019) \\
& $52 \mathrm{~km}$ & MRI020 & NCM056 \\
\end{tabular}

in TC seed frequency is related to that of SST (Vecchi et al. 2019). We used the outputs of the tier 1 and 3 simulations but not tier 2 simulation which may complicate comparison due to difference in SST response between models. The tier 1 simulation spanned from 1950 to 2014, in which SST and sea ice forcing were based on Hadley Centre Sea Ice and SST data sets (HadISST2; Titchner and Rayner 2014). The tier 3 simulation spanned from 2015 to 2050, in which the change rate of SST and sea ice forcing were derived from the ensemble mean of the Coupled Model Intercomparison Project Phase 5 Representative Concentration Pathways 8.5 scenario. The interannual variability was derived from the observed historic 1950 to 2014 period (Haarsma et al. 2016). The methodology broadly followed that of Mizuta et al. (2008).

An exception to the simulation period was utilized for NCM014. NCM014 is composed of three 11-year simulation periods: 1950-1960, 2000-2010, and 2040-2050. Hence, we excluded NCM014 from the trend analysis and took precautions when comparing between results of NCM14 and the other models. Although some models such as HadGEM3-GC3.1 have multiple ensemble members, we used a single ensemble member for each model (r1i1p1f1) in the present study.

\subsection{Tropical cyclone detection method}

To detect TCs in each model, we used TempestExtremes (Ullrich and Zarzycki 2017; Zarzycki and Ullrich 2017). TempestExtremes uses two steps to detect TCs: in the first step, the algorithm gathers TC candidates for each time step; in the second step, these candidates are connected between sequential time steps. In these steps, we can flexibly select variables and their criteria. In the present study, we followed the configuration of Roberts
(2019) and Roberts et al. (2019b, 2020), in which the featured tracking variable is sea level pressure (SLP) on the native analysis grid.

At the first step, the algorithm identifies candidates based on local SLP minima with a warm core, which is defined as the geopotential height difference $(250-500 \mathrm{hPa})$. Simultaneously, these candidates must satisfy four criteria: (i) these candidates must have a closed contour of SLP within $5.5^{\circ}$ of each candidate, (ii) the SLP of a candidate node must be $2 \mathrm{hPa}$ lower than that on its closed contour, (iii) the candidate must have a closed contour of geopotential height difference $(250-500 \mathrm{hPa})$ within $6.5^{\circ}$ of the candidate, and (iv) the geopotential height difference maximum within $1^{\circ}$ of the candidate should be $6 \mathrm{~m}$ larger than the geopotential height difference on the closed circle.

At the next step, TempestExtremes forms the paths of the candidates at different time steps. These paths must include at least ten candidates while permitting a maximum gap size of three, which is the number of time steps where no identification occurred. The TC lifetime must be more than $60 \mathrm{~h}$. In addition, the TC must form between $10^{\circ} \mathrm{S}-40^{\circ} \mathrm{S}$ or $10^{\circ} \mathrm{N}-40^{\circ} \mathrm{N}$ and must travel at least $8^{\circ}$. The distance between candidates must be less than $8^{\circ}$. The criterion of topography excludes the path in which candidates exist (i) more than ten timesteps over the topographic height of $1500 \mathrm{~m}$ and (ii) more than four time steps over the topographic height over $10 \mathrm{~m}$. These paths are considered a storm trajectory. The first point in each trajectory is defined as the genesis of TC.

\subsection{Definition of tropical cyclone seed}

In the present study, we define the candidates that TempestExtremes detected at the first step as TC seeds. This also includes TCs. The SR is defined as 


$$
\mathrm{SR} \equiv \frac{N_{T C}}{N_{\text {seed }}}
$$

where $N_{\text {TC }}$ and $N_{\text {seed }}$ indicate the annual frequencies of TC genesis and seeds, respectively. It is important to note that $N_{\text {TC }}$ is counted by the genesis number, while $N_{\text {seed }}$ is counted by the existence number (the total number of candidates) within $40^{\circ} \mathrm{S}-40^{\circ} \mathrm{N}$. In practice, some TC seeds will exist across a few time steps. These consist of a few candidates. In the definition of $N_{\text {seed }}$ in this study, these candidates were not counted as one TC seed but as multiple TC seeds. Therefore, the definition of $N_{\text {seed }}$ used in this study overestimates the number of TC seeds.

Tory et al. (2018) evaluated a relationship between TC and tropical depression (TD) which may develop into TC by using ERA-I. They detected TC and TD with the Okubo-Weiss-Zeta parameter TC detection scheme (Tory et al. 2013a, 2013b). The difference between TC and TD is minimum time period in which the disturbance satisfies six thresholds (see Table 2 of Tory et al. 2018). The time period is $48 \mathrm{~h}$ for TC, and $24 \mathrm{~h}$ for TD. As TD can be regard as TC seed, their method can avoid the overestimation of $N_{\text {seed }}$. However, Tory et al. (2018) suggested that TD are difficult to define. The minimum lifetime of TC seed seems to be also difficult to define. In the present study, we simply define the candidates in the first step of TempestExtremes as TC seed.

\subsection{Best track and reanalysis}

We used the International Best Track Archive for Climate Stewardship (IBTrACS) version 04r00 (Knapp et al. 2010, 2018) to assess TC frequency and geographical distribution. This dataset consisted of the "best tracks" provided by many agencies, covering global storm activity. The dataset included not only TCs but also other storms, i.e., disturbance, subtropical-, and extra-tropical cyclones. In our analysis, we choose TCs of which a 1-min maximum sustained wind speed exceeds $17.5 \mathrm{~ms}^{-1}$ in the IBTrACS. The wind speed was based on data reported by the national Hurricane Center (Jarvinen et al. 1984) and the Joint Typhoon Warning Center (Chu et al. 2002). We used the IBTrACS between 1980 and 2014.

To the best of our knowledge, there are no available global TC seeds datasets. Hurley and Boo (2014) presented the first global climatology of monsoon lowpressure systems based on the European Centre for Medium-Range Weather Forecasts (ECMWF) Interim Re-Analysis (ERA-I; Dee et al. 2011). These are regarded as systems that may become TCs. Murakami (2014) and Hodges et al. (2017) showed that the Japanese 55-year reanalysis (JRA-55; Kobayashi et al. 2015; Harada et al. 2016) is the best in terms of its representation of TC frequency in state-of-the-art reanalysis data. For assessing TC seed frequency and its geographical distribution, we used three reanalyses: ERA-I, JRA-55, and the fifth-

Table 2 Spearman's rank correlations between TC genesis frequencies in HighResMIP multi models and in reanalyses, and IBTrACS. Spearman's rank correlations were calculated from 1980 to 2014. An asterisk indicates that a correlation is statistically significant at the $90 \%$ confidence level (at least). $P$ values are indicated in parentheses

\begin{tabular}{llll}
\hline Model/Analysis & Globe & Northern Hemisphere & Southern Hemisphere \\
\hline CNRM156 & $0.030(0.864)$ & $-0.120(0.494)$ & $0.090(0.609)$ \\
CNRM055 & $0.216(0.214)$ & $0.234(0.175)$ & $.111(0.526)$ \\
EC078 & $0.162(0.353)$ & $0.087(0.619)$ & $-0.070(0.690)$ \\
EC039 & $-0.007(0.969)$ & $0.059(0.738)$ & $0.018(0.919)$ \\
MPI100 & $0.181(0.298)$ & $0.103(0.555)$ & $-0.211(0.224)$ \\
MPI052 & $-0.047(0.790)$ & $-0.168(0.334)$ & $-0.125(0.474)$ \\
MRI060 & $0.203(0.242)$ & $0.200(0.249)$ & $-0.161(0.355)$ \\
MRI020 & $0.099(0.571)$ & $0.102(0.561)$ & $-0.028(0.874)$ \\
HG208 & $0.116(0.507)$ & $0.200(0.250)$ & $0.327(0.055)$ \\
HG093 & $-0.063(0.721)$ & $0.104(0.554)$ & $-0.124(0.476)$ \\
HG039 & $0.138(0.429)$ & $0.202(0.245)$ & $0.217(0.211)$ \\
NCM056 & $0.152(0.384)$ & $0.195(0.262)$ & $-0.065(0.712)$ \\
NCM028 & $0.236(0.172)$ & $* 0.290(0.091)$ & $0.099(0.571)$ \\
MME mean & $0.136(0.436)$ & $0.049(0.780)$ & $-0.051(0.773)$ \\
MME median & $0.131(0.453)$ & $0.114(0.514)$ & $-0.043(0.807)$ \\
ERA-I & $* 0.577(<0.001)$ & $* 0.662(<0.001)$ & $-0.017(0.922)$ \\
JRA-55 & $* 0.535(0.001)$ & $* 0.492(0.003)$ & $* 0.466(0.005)$ \\
ERA-5 & $* 0.333(0.050)$ & $* 0.501(0.002)$ & $0.158(0.364)$ \\
\hline
\end{tabular}


generation ECMWF reanalysis (ERA-5: Copernicus Climate Change Service 2017). We applied TempestExtremes to ERA-I, JRA-55, and ERA-5 to count TC seeds in the same manner as that for the HighResMIP simulation output.

\subsection{Statistical analysis}

We employed the nonparametric Mann-Kendall test for detecting time series trends in TC genesis frequency, seed frequency, and SR. Spearman's rank correlations were calculated between TC genesis frequencies in the HighResMIP simulations and IBTrACS, and between TC seed frequencies in the HighResMIP simulations and JRA-55. We also calculated Spearman's rank correlations between three parameters: TC genesis frequency, seed frequency, and SR. The responses of the three parameters to global warming were assessed with the Wilcoxon rank-sum test. These statistical analyses were performed using Python libraries (Oliphant, 2007; Millman and Aivazis 2011; Hussain and Mahmud 2019).

\section{Results}

\subsection{Tropical cyclone frequencies}

Figure 1 shows the horizontal distributions of normalized TC genesis density for IBTrACS, ERA-I, JRA-55, ERA-5, and each model (non-normalized TC genesis densities are seen in Supplemental Fig. 1). Except in NCM014, this density was defined as the number of TCs per year generated in a $5^{\circ} \times 5^{\circ}$ grid box between 1990 and 2014. In NCM014, the period spanned from 2000 to 2009. Each model represented a broadly realistic geographical distribution compared with IBTrACS (Fig. 1a), although most models showed fewer or more annual TC genesis frequencies than that of the best track. With the exception of NCM056 (Fig. 1p), the lowest resolution version of each model underestimated global annual mean TC genesis frequency (Fig. 1e, g, i, k, and m). In general, the frequencies in the higher-resolution versions were increased (Fig. 1f, h, j, l, n, o, q, and r) compared with the lower-resolution versions (Fig. 1e, g, i, k, m, and p), which is consistent with the results of Roberts et al. (2019b). With the settings used in this study, TempestExtremes showed little discrepancy in global annual mean genesis frequency between CNRM055 and IBTrACS. This may leave room for improvement in terms of tuning the TempestExtremes criteria to the other models, but this would complicate inter-model comparison and is outside the scope of the present study.

Figure 2 shows the interannual variability of the normalized annual TC genesis frequency for IBTrACS, ERA-I, JRA-55, ERA-5, and multi-models (except for NCM014). Since global annual TC genesis frequencies substantially varied between the models and their horizontal resolutions (Fig. 1), we normalized the annual TC genesis frequencies of the models, ERA-I, JRA-55, ERA-
5, and IBTrACS based on their mean values from 1990 to 2014 for the respective data. Table 2 shows the Spearman's rank correlation of each model and reanalyses with IBTrACS during the period in which available period of IBTrACS overlapped tier 1 period; i.e., 19802014. There were no significant positive correlations between the multi-model ensemble (MME) and IBTrACS for TC genesis frequency in either hemisphere or the entire globe.

As for the individual models, some models showed weak or moderate correlations, which appeared to increase with decreasing horizontal grid interval in some models (especially in the North Atlantic; Supplemental table 1). However, we should not regard this impact of horizontal resolution as an improvement. Roberts et al. (2019b) noted that a single member of a model is insufficient for evaluating the impact of horizontal resolution on interannual variability. They suggested that at least six members are required for robust basin-scale correlations.

JRA-55 showed a statistically significant correlation with IBTrACS for the globe (correlation coefficient: 00.54, $p$ value: 0.001), for the Northern Hemisphere (correlation coefficient: $0.49, p$ value: 0.003 ), and for the Southern Hemisphere (correlation coefficient: 0.47, $p$ value: 0.005 ). ERA-I and ERA-5 also showed a statistically significant correlation with IBTrACS for the globe and the Northern Hemisphere except for the Southern Hemisphere. Supplemental table 1 lists correlation coefficients for individual ocean basins. JRA-55 has statistically significant correlation in all ocean basins except the South Atlantic, which are higher than those of the other reanalyses except for the North Atlantic. JRA-55 well captures the interannual variability of the observed TC genesis frequency. As Murakami (2014) suggested, JRA55 properly represents the interannual variation of TC frequency, which encourages the use of JRA-55 in the present study.

As for future changes in TC genesis frequency due to global warming, after 2039, approximately $75 \%$ of the models projected a decrease in the global TC genesis frequency compared with their mean value between 1990 and 2014 (Fig. 2a). Consistent with Roberts et al. (2020), the decreasing trend was clear in the Southern Hemisphere (Fig. 2c), whereas the trend in the Northern Hemisphere was unclear (Fig. 2b).

Table 3 summarizes the trends in TC genesis frequency from 1990 to 2049 for the individual models. Except for MPI100, MPI052, and HG039, the models projected a decreasing trend in global TC frequency. These decreasing trends were statistically significant at the 90\% confidence level (at least) for CNRM055, MRI060, MRI020, NCM056, and NCM028. The increasing trends in MPI100, MPI052, and HG039 were not 


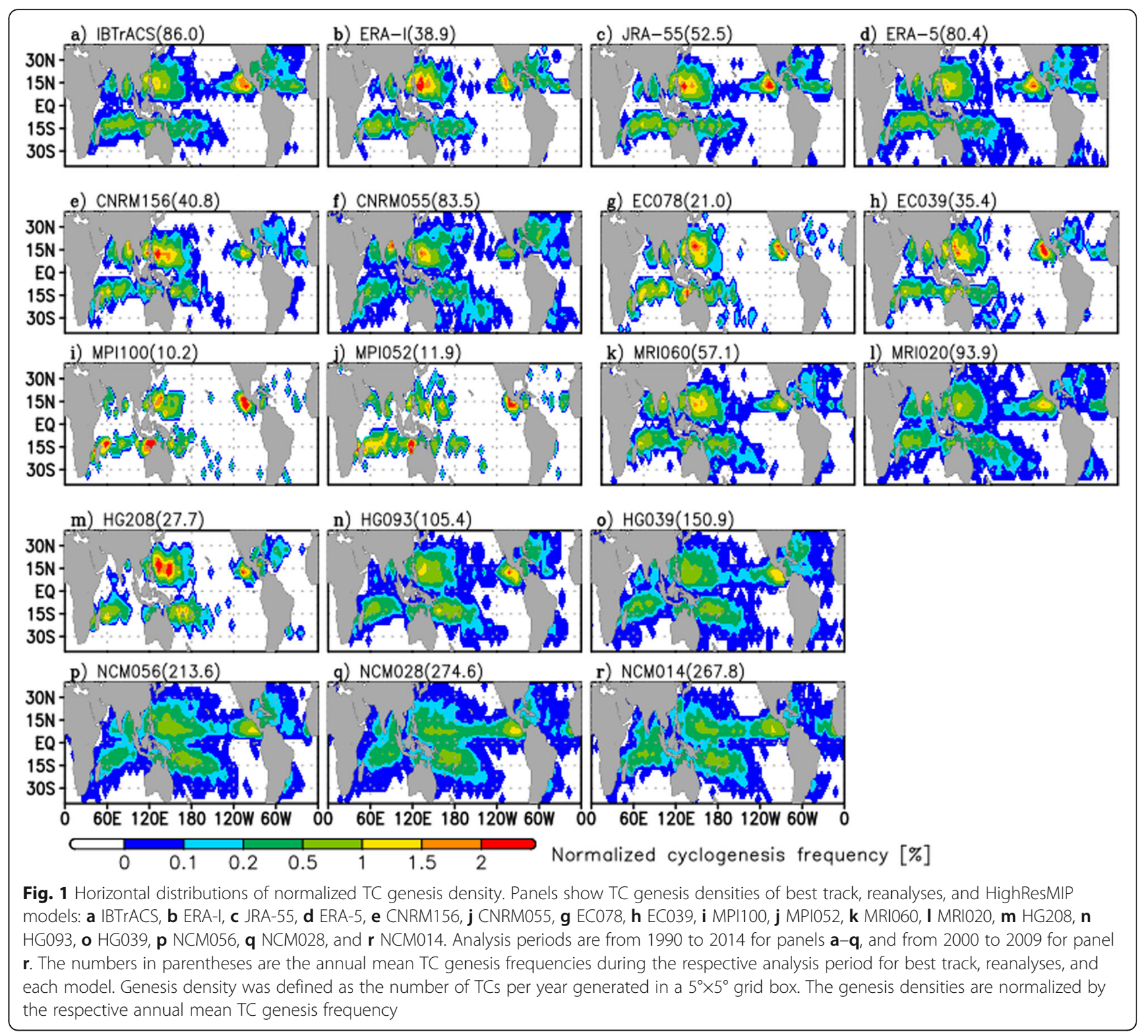

statistically significant. As a result, the MME mean and median showed a statistically significant decreasing trend with at the $90 \%$ confidence level (at least).

Figure 3 shows the spatial distributions of fractional change in TC genesis density. Although the spatial distribution of future change differs between models, Fig. 3 represents some similar characteristics among models, which might reflect their responses to a specific external condition such as SST. For instance, in most models, TC genesis frequency becomes more active near the west coast of Africa, the west coast of North America, the north-west coast of Australia, and Madagascar. On the other hand, TC activity becomes inactive over the central South Pacific, the central Indian Ocean, and the west side of the date line. The regions of decreasing TC genesis negate those with increases, which leads to the decreasing trend (Fig. 2).

\subsection{TC seed frequencies}

The time series of normalized annual TC seed frequency is seen in Fig. 4. Inter-model variability in the annual TC seed frequency appeared to be smaller than that of annual TC frequency (Fig. 2). This may be attributed to the fact that ratio of variation of mean values in TC genesis frequency is larger than those of TC seed frequency for all models. TC seed frequency in the MME median had a significant positive correlation with that of JRA-55 over the Northern Hemisphere and a significantly negative correlation over the Southern Hemisphere. The TC frequency in JRA-55 significantly correlated with that of 


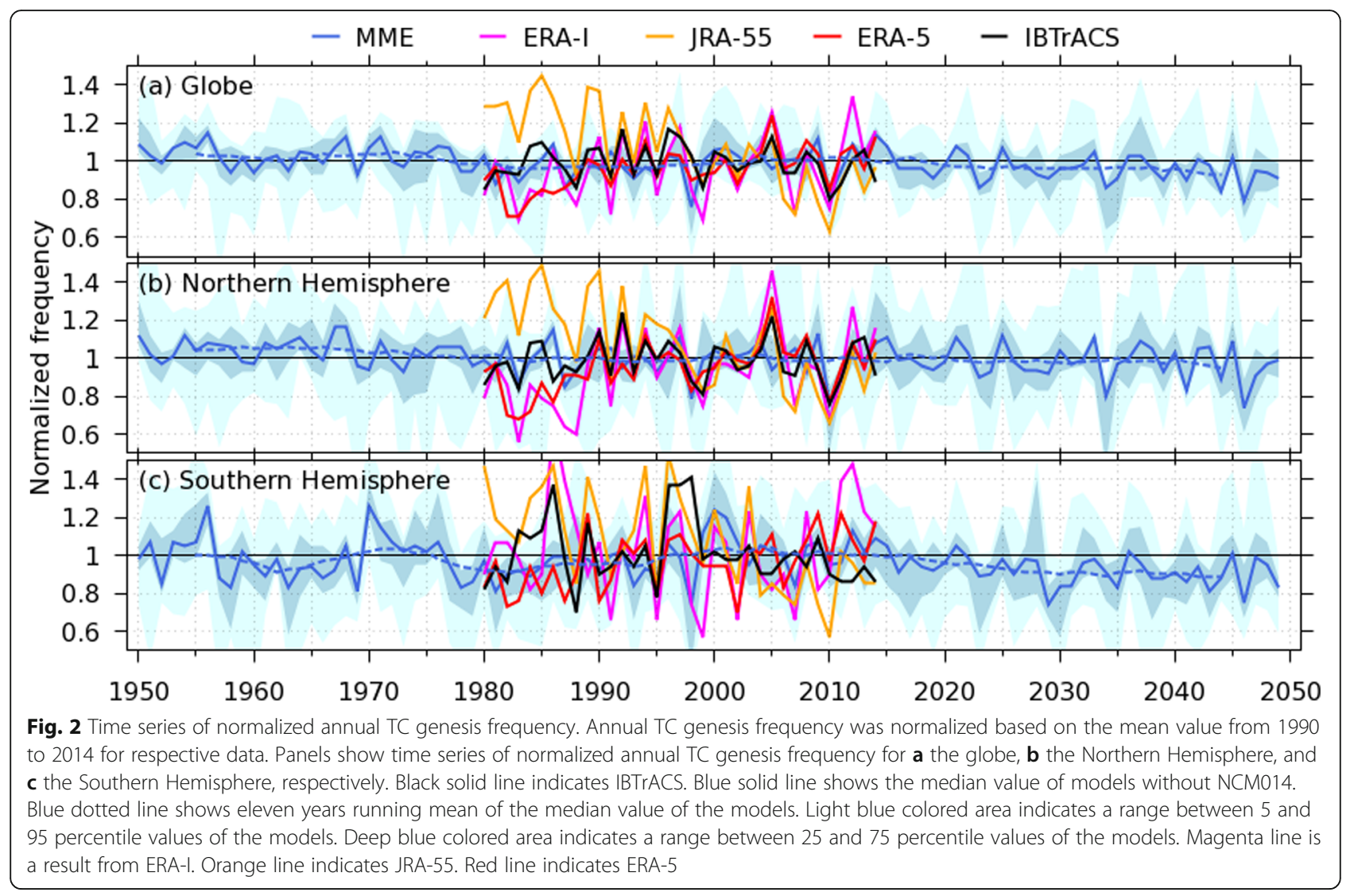

Table 3 Trends in TC genesis, TC seed frequency, and survival rate (SR). Trends were calculated from 1990 to 2049. An asterisk indicates that a trend is statistically significant at the $90 \%$ confidence level (at least) with the nonparametric Mann-Kendal test. $P$ values are indicated in parentheses

\begin{tabular}{llll}
\hline Model & TC genesis & Seed & SR \\
\hline CNRM156 & $-0.09(0.298)$ & $*_{-}-0.22(0.014)$ & $0.08(0.342)$ \\
CNRM055 & $*_{-0.21(0.016)}$ & $*_{-}-0.32(<0.001)$ & $0.10(0.241)$ \\
EC078 & $-0.11(0.234)$ & $-0.09(0.287)$ & $-0.07(0.403)$ \\
EC039 & $-0.10(0.280)$ & $-0.11(0.207)$ & $-0.04(0.660)$ \\
MPI100 & $0.01(0.913)$ & $0.12(0.170)$ & $-0.05(0.583)$ \\
MPI052 & $0.08(0.397)$ & $-0.10(0.246)$ & ${ }^{*} 0.19(0.030)$ \\
MRI060 & $*-0.18(0.045)$ & $*-0.18(0.046)$ & $0.04(0.619)$ \\
MRI020 & $*-0.19(0.030)$ & $*-0.32(<0.001)$ & $0.14(0.104)$ \\
HG208 & $-0.03(0.725)$ & $-0.02(0.818)$ & $-0.04(0.642)$ \\
HG093 & $-0.14(0.115)$ & $*-0.18(0.042)$ & $0.01(0.914)$ \\
HG039 & $0.04(0.687)$ & $-0.11(0.235)$ & $* 0.16(0.065)$ \\
NCM056 & $*-0.27(0.003)$ & $*-0.28(0.001)$ & $-0.08(0.355)$ \\
NCM028 & $*-0.28(0.001)$ & $*-0.26(0.003)$ & $*-0.24(0.006)$ \\
MME mean & $*-0.15(0.093)$ & $*-0.23(0.010)$ & $0.01(0.944)$ \\
MME median & $*-0.19(0.034)$ & $*-0.27(0.003)$ & $0.06(0.536)$ \\
\hline
\end{tabular}

IBTrACS in the globe and both hemisphere (see Table 2). Therefore, we calculated the correlation coefficients between each model and JRA-55 (Table 4). The annual global TC seed frequencies of the MME median and mean did not correlate with those of JRA-55 as well as did TC genesis frequency.

As for the individual models, correlation coefficients between each model and JRA-55 are listed in Table 4. NCM028 showed a moderate positive correlation with JRA-55 across the globe (0.49) and in the Northern Hemisphere (0.46), whereas CNRM055, MRI060, and NCM056 did so only in the Northern Hemisphere (0.35, 0.31 , and 0.38, respectively). MPI100, MPI052, and HG093 showed moderate negative correlations in the Southern Hemisphere $(-0.46,-0.51$, and -0.33 , respectively). MPI100 also showed a moderate negative correlation across the globe $(-0.38)$.

As for the trend in $\mathrm{TC}$ seed frequency, the mean and median values of MME showed statistically significant decreasing trends at the $90 \%$ level (at least) across the globe (Table 3). These decreasing trends were seen in both hemispheres (Fig. 4). The decreasing trend in global TC seed frequency was consistent with that of TC genesis frequency; i.e., the sign of the trends in TCs and seeds coincided with each other. As for the individual models, trends were consistent between TC and seed 


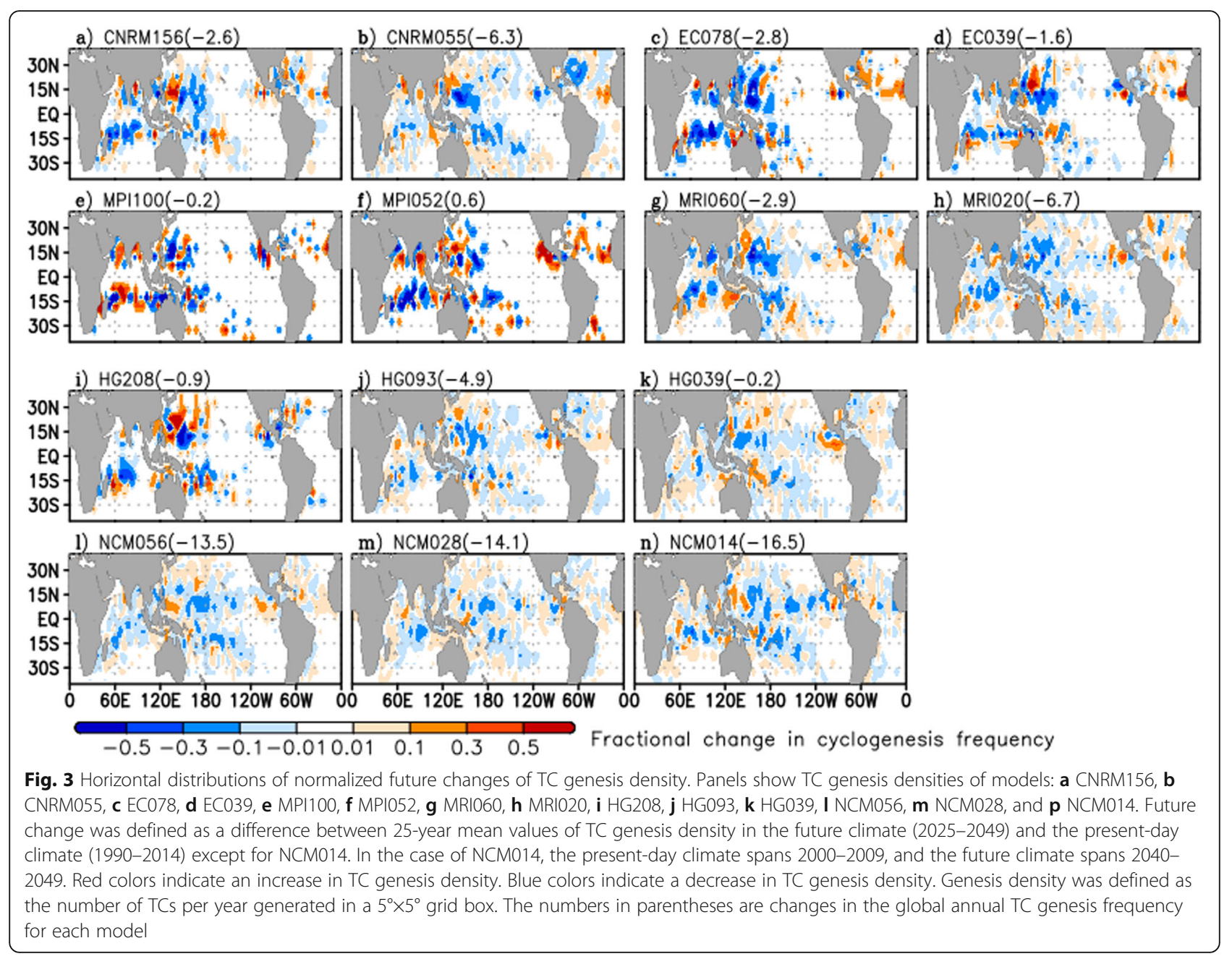

frequency for all models except MPI052 and HG039. In the cases of MPI052 and HG039, SR might overwhelm the decrease in TC seed frequency.

To examine the consistency of the horizontal distribution between future fractional changes in the frequencies of TC genesis and TC seeds, Fig. 5 shows the geographical distributions of future changes in TC seed frequency (Supplemental Figures 2 and 3 shows a TC existence density in the present-day climate, and a normalized TC existence density, respectively). The geographical distributions of the fractional change in TC seeds and genesis were similar for each model (Figs. 3 and 5). However, in some regions, the change in TC seed frequency showed opposite sign to that of TC genesis frequency (e.g., the East China Sea). In general, the change in TC seed frequency was spatially noisier than that of TC genesis frequency, which is attributed to different definition of density. In Fig. 3, only the TC genesis location is considered.

The behavior of TC seed frequency was similar to that of TC genesis frequency in terms of time series and horizontal distribution. This suggests that TC seed frequency contributed to TC genesis frequency.

\subsection{Survival rate}

We considered the ratio of TC frequency to TC seed frequency as the SR (Eq. 1). The SR varied interannually as well as TC genesis and its seed frequencies (data not shown). Table 3 summarizes the trend in the SR for each model. The SR showed statistically significant increasing trends at the 90\% confidence level (at least) for MPI052 and HG039, and a decreasing trend for NCM028. The other models did not show statistically significant trends. The trends in SR showed the opposite sign to those of TC genesis frequency in CNRM156, CNRM055, MPI100, MRI060, MRI020, HG093, and HG039, although the trends between them showed the same sign in EC078, EC039, MPI052, HG208, NCM056, and NCM028. These results suggest that the change in TC frequency is associated with both $\mathrm{TC}$ seed frequency and SR, with the dominant factor depending on the model. In the following subsection, we quantify the 


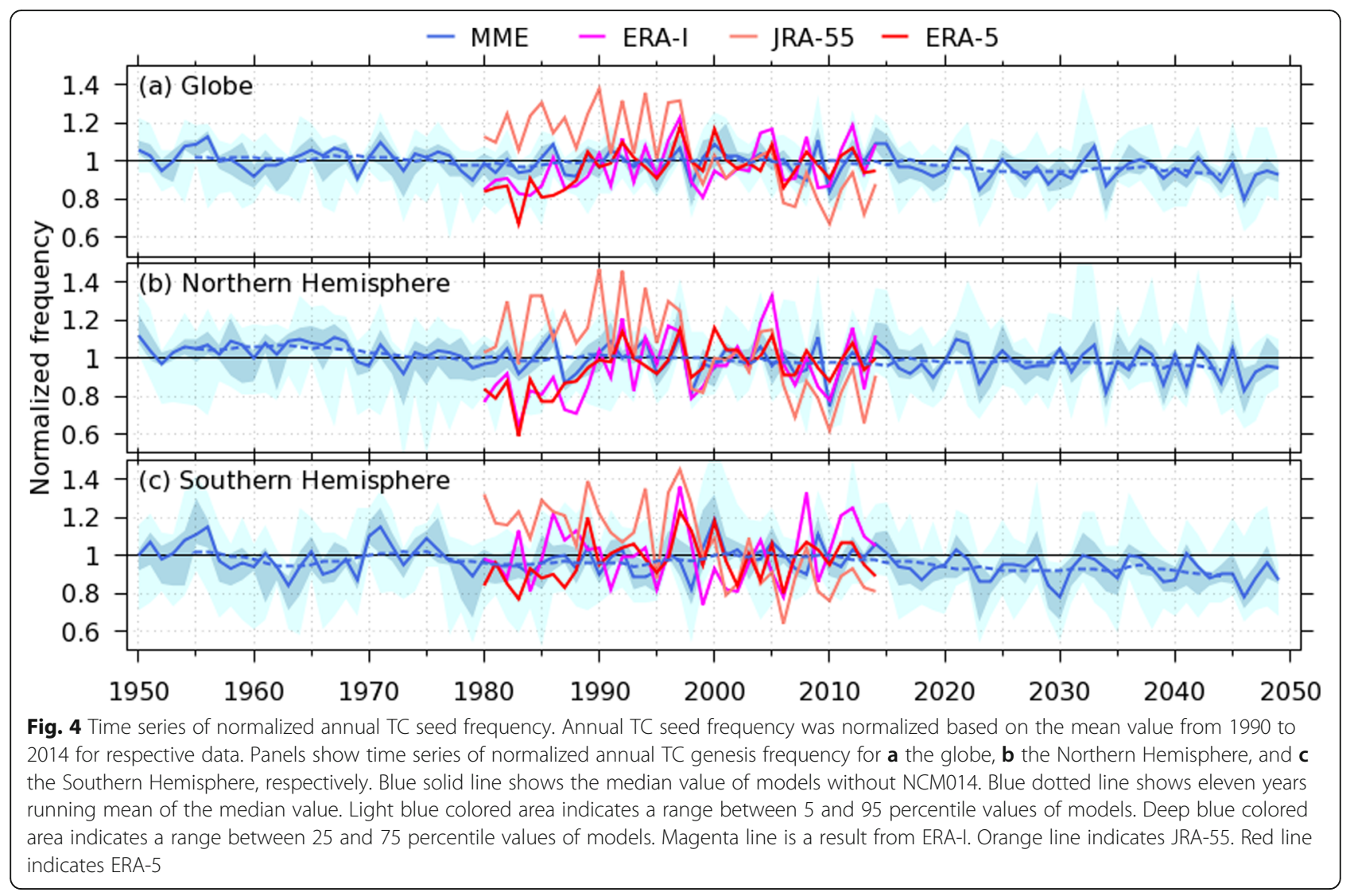

Table 4 Spearman's rank correlations between TC seed frequencies in HighResMIP multi models and in JRA-55. Spearman's rank correlations were calculated from 1980 to 2014. An asterisk indicates that a correlation is statistically significant at the $90 \%$ confidence level (at least). $P$ values are indicated in parentheses

\begin{tabular}{llll}
\hline Model & Globe & Northern Hemisphere & Southern Hemisphere \\
\hline CNRM156 & $0.145(0.406)$ & $0.133(0.445)$ & $-0.024(0.891)$ \\
CNRM055 & $0.233(0.178)$ & ${ }^{*} 0.345(0.042)$ & $0.038(0.828)$ \\
EC078 & $-0.029(0.869)$ & $0.070(0.689)$ & $-0.164(0.346)$ \\
EC039 & $-0.054(0.756)$ & $-0.021(0.906)$ & $-0.167(0.338)$ \\
MPI100 & $*-0.381(0.024)$ & $-0.033(0.852)$ & $*-0.457(0.006)$ \\
MPI052 & $-0.258(0.135)$ & $0.014(0.937)$ & $*-0.506(0.002)$ \\
MRI060 & $0.190(0.274)$ & $* 0.309(0.071)$ & $-0.130(0.455)$ \\
MRI020 & $0.065(0.711)$ & $0.231(0.182)$ & $-0.117(0.502)$ \\
HG208 & $0.225(0.194)$ & $0.264(0.125)$ & $0.192(0.268)$ \\
HG093 & $-0.063(0.717)$ & $0.197(0.257)$ & $*-0.328(0.055)$ \\
HG039 & $0.111(0.527)$ & $0.263(0.126)$ & $-0.154(0.377)$ \\
NCM056 & $0.243(0.159)$ & ${ }^{0} 0.379(0.025)$ & $0.132(0.451)$ \\
NCM028 & $* 0.490(0.003)$ & $* 0.456(0.006)$ & $0.259(0.133)$ \\
MME mean & $0.015(0.934)$ & $0.221(0.202)$ & $*-0.326(0.056)$ \\
MME median & $0.069(0.694)$ & $*^{*} 0.333(0.050)$ & $*-0.303(0.077)$ \\
\hline
\end{tabular}




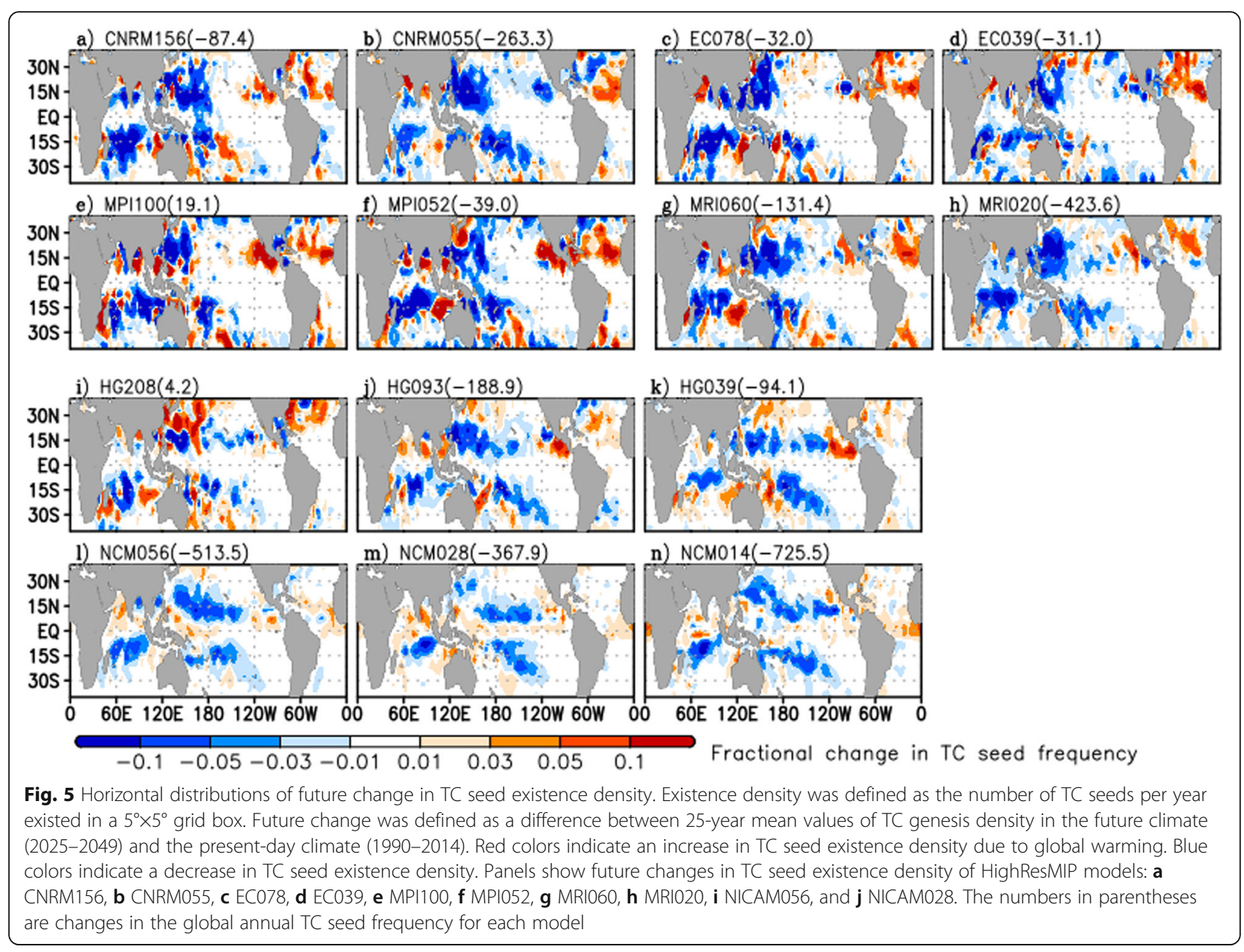

relationships between TC genesis frequency, TC seed frequency, and SR.

\subsection{Relationships between each parameter}

To quantify the relationships between annual TC genesis frequency, seed frequency, and SR, Table 5 lists the correlation coefficients between these three parameters from 1950 to 2049. As for TC genesis and its seed frequency, CNRM-CM6, EC-Earth3P, MRI-AGCM3, HadGEM3-GC3.1, and NICAM.16-S showed strong, statistically significant correlations (greater than 0.7 ) at the 99.9\% confidence level, whereas MPI-ESM1.2 showed only a moderate correlation (0.65). Correlations for single models were almost unchanged for different horizontal resolutions. In the reanalyses, the correlation coefficients were strong ( 0.87 for JRA-55 and 0.86 for ERA-I), and moderate (0.65 for ERA-I). In addition, TC genesis frequency in IBTrACS showed a moderate correlation with TC seed frequency which is substitution from JRA-55. These findings suggest that TC seed frequency strongly affects TC genesis frequency.
In terms of TC genesis frequency and SR, EC078, MPI-ESM1.2, HG208, NCM028, and NCM014 showed strong, statistically significant correlations (greater than 0.7 ) at the $99.9 \%$ confidence level. CNRM156, EC039, MRI-AGCM3, HG093, HG039, and NICA M056 showed moderate correlations $(0.4-0.7)$ at the 99.0\% confidence level (at least). CNRM055 showed a weak correlation (0.33). Differing from TC seed, the correlation of SR with TC frequency in CNRM-CM6 varied substantially between horizontal resolutions. In the reanalyses, JRA-55 showed a weak correlation (0.37), whereas ERA-I and ERA-5 showed a moderate correlation $(0.65$ and 0.43$)$. In IBTrACS, there was a moderate correlation (0.47). Most models and reanalyses showed that TC seed frequency exhibited a stronger relation to TC genesis than to SR (except for MPI-ESM1.2 and HG208).

On the other hand, TC seed frequency and SR show generally weaker correlations compared with other pairs of parameters. This indicates that SR may be independent of TC seed frequency. 
Table 5 Spearman's rank correlations between TC genesis frequency, TC seed frequency, and survival rate (SR) in each model and reanalysis

\begin{tabular}{|c|c|c|c|}
\hline Model/Analysis & Seed vs. TC & SR vs. TC & Seed vs. SR \\
\hline CNRM156 & $*^{*} 0.80(<0.001)$ & ${ }^{*} 0.64(<0.001)$ & $0.08(0.428)$ \\
\hline CNRM055 & ${ }^{*} 0.79(<0.001)$ & ${ }^{*} 0.33(0.001)$ & * $-0.24(0.015)$ \\
\hline EC078 & ${ }^{*} 0.79(<0.001)$ & ${ }^{*} 0.75(<0.001)$ & ${ }^{*} 0.24(0.015)$ \\
\hline EC039 & ${ }^{*} 0.83(<0.001)$ & ${ }^{*} 0.63(<0.001)$ & $0.14(0.152)$ \\
\hline MPI100 & ${ }^{*} 0.65(<0.001)$ & ${ }^{*} 0.84(<0.001)$ & ${ }^{*} 0.18(0.080)$ \\
\hline MPI052 & ${ }^{*} 0.65(<0.001)$ & ${ }^{*} 0.75(<0.001)$ & $0.03(0.734)$ \\
\hline MRI060 & ${ }^{*} 0.81(<0.001)$ & ${ }^{*} 0.48(<0.001)$ & $-0.08(0.414)$ \\
\hline MRI020 & ${ }^{*} 0.77(<0.001)$ & ${ }^{*} 0.43(<0.001)$ & * $-0.17(0.083)$ \\
\hline HG208 & ${ }^{*} 0.75(<0.001)$ & ${ }^{*} 0.80(<0.001)$ & ${ }^{*} 0.25(0.011)$ \\
\hline HG093 & ${ }^{*} 0.78(<0.001)$ & ${ }^{*} 0.67(<0.001)$ & $0.12(0.247)$ \\
\hline HG039 & ${ }^{*} 0.80(<0.001)$ & ${ }^{*} 0.60(<0.001)$ & $0.06(0.553)$ \\
\hline NCM056 & ${ }^{*} 0.91 \quad(<0.001)$ & ${ }^{*} 0.69(<0.001)$ & ${ }^{*} 0.35(<0.001)$ \\
\hline NCM028 & ${ }^{*} 0.80(<0.001)$ & ${ }^{*} 0.76(<0.001)$ & ${ }^{*} 0.26(0.008)$ \\
\hline NCM014 & ${ }^{*} 0.91(<0.001)$ & ${ }^{*} 0.74(<0.001)$ & ${ }^{*} 0.42(0.019)$ \\
\hline ERA-I & ${ }^{*} 0.86(<0.001)$ & ${ }^{*} 0.65(<0.001)$ & ${ }^{*} 0.29(0.093)$ \\
\hline JRA-55 & ${ }^{*} 0.87(<0.001)$ & ${ }^{*} 0.37(0.030)$ & $-0.08(0.664)$ \\
\hline ERA-5 & ${ }^{*} 0.65(<0.001)$ & ${ }^{*} 0.43(<0.001)$ & * $-0.34(0.044)$ \\
\hline IBTrACS & ${ }^{*} 0.51(0.002)$ & $-0.08(0.659)$ & ${ }^{*}-0.88(<0.001)$ \\
\hline
\end{tabular}

Spearman's rank correlations between the three parameters (TC, seed, and SR) were calculated from 1950 to 2049 for models except for NCM014, and from 1980 to 2014 for JRA-55, ERA-I, and IBTrACS. The TC seed of IBTrACS was substituted by that of JRA-55. The correlation in NCM014 was calculated during the periods for which the data are available: 1950-1960, 2000-2009, and 2040-2049. An asterisk indicates that a correlation is statistically significant at the $90 \%$ confidence level (at least). $P$ values are indicated in parentheses

\section{Discussion}

In the present study, we examined the responses of three parameters (TC genesis frequency, TC seed frequency, and SR) to global warming, as well as their interrelationships, using the output of the HighResMIP multi-model simulation. TC genesis frequency appeared to be associated with TC seed frequency and SR. Here, we discuss contributions of TC seed frequency and SR to a change in TC genesis frequency due to global warming, as well as the influences of model type and horizontal grid interval on the three parameters.

\subsection{Contributions of TC seed and survival rate to future changes in TC genesis frequency}

To quantify the contributions of TC seed and SR, we defined the present-day climate as the period from 1990 to 2014 (the last 25 years of the tier 1 experiment) and the future climate as the period from 2025 to 2049 (the last 25 years of the tier 3 experiment). We calculated their contributions to the change in TC genesis frequency between two climate conditions for each model and horizontal resolution. In NCM014, we regard 2000-2009 as the present-day climate, and 2040-2049 as the future climate. In this study, we simply define the relationship between TC genesis frequency $\left(N_{T C}\right)$, TC seed frequency $\left(N_{\text {seed }}\right)$, and SR as that shown in Eq. 1 . Considering future changes in TC genesis frequency due to global warming, Eq 1 is rewritten as follows:

$$
\frac{\Delta N_{\mathrm{TC}}}{N_{\mathrm{TC}}}=\frac{\Delta N_{\text {seed }}}{N_{\text {seed }}}+\frac{\Delta \mathrm{SR}}{\mathrm{SR}}+\text { Residual },
$$

where $\Delta$ indicates difference in each parameter between the future climate and the present-day climate. The denominators are the mean values in the presentday climate for each parameter. Each term in Eq. 1 indicates fractional changes in the three parameters due to global warming: TC frequency $\left(\Delta N_{\mathrm{TC}} /_{N_{\mathrm{TC}}}\right)$, seed frequency $\left(\Delta N_{\text {seed }} / N_{\text {seed }}\right)$, SR $(\Delta \mathrm{SR} / \mathrm{SR})$, and residual.

Table 6 lists the fractional changes for each model as well as the mean values of TC (number year ${ }^{-1}$ ), TC seed (number year $^{-1}$ ), and SR (\%) the present-day climate. Similar to the trends described in Section 3, these changes varied among the models. Even in individual models, the amplitude or sign of change varied among horizontal resolutions and was not systematic. Statistically significant decreases were detected in (i) TC genesis frequency for CNRM055, MRI020, NCM056, NCM028, and NCM014; (ii) TC seed frequency for CNRM156, CNRM055, MRI060, MRI020, NCM056, NCM028, and NCM014; and (iii) SR for only NCM028. Figure 6 visually presents these fractional changes. These plots show that the contributions of seed frequency and SR to TC frequency varied among the models and their resolutions. In CNRM-CM6 and MRI-AGCM3, a decrease in seed frequency overwhelmed the increase in $\mathrm{SR}$, with the impact of the decrease in seed becoming conspicuous at finer resolutions. In NICAM.16-S, both seed frequency and SR simultaneously played a role in decreasing TC frequency, with the magnitude of their contribution varying with horizontal resolution. In ECEarth3P, MPI-ESM1.2, and HadGEM3-GC3.1, the sign and magnitude of each parameter nonlinearly differed between horizontal resolutions. As these three models did not show significant changes in each parameter, it is unclear whether change in seed frequency or SR (or both) controlled changes in TC frequency. Based on the results from CNRM-CM6, MRI-AGCM3, and NICA M.16-S, the decrease in seed frequency appeared to be a main contributor to the decrease in TC frequency.

Vecchi et al. (2019) and Sugi et al. (2020) reported opposite signs for changes in seed frequency when using different definitions for the seeds and different models. Our results also show different signs between models and horizontal resolutions in spite of using a specific 
Table 6 Fractional changes in TC genesis frequency, TC seed frequency, and SR

\begin{tabular}{|c|c|c|c|c|c|c|c|}
\hline \multirow[t]{2}{*}{ Model } & \multicolumn{2}{|l|}{ TC } & \multicolumn{2}{|l|}{ Seed } & \multicolumn{2}{|l|}{ SR } & \multirow{2}{*}{$\begin{array}{l}\text { Resi } \\
\Delta[\%]\end{array}$} \\
\hline & $\Delta[\%]$ & $P_{\text {mean }}$ & $\Delta[\%]$ & $P_{\text {mean }}$ & $\Delta[\%]$ & $P_{\text {mean }}$ & \\
\hline CNRM156 & -6.27 & 40.8 & ${ }^{*}-8.44$ & 1034.7 & 2.16 & 3.9 & -0.01 \\
\hline CNRM055 & -7.57 & 83.5 & $*-9.66$ & 2725.5 & 2.08 & 3.1 & -0.01 \\
\hline EC078 & -13.12 & 21.0 & -8.10 & 394.7 & -5.00 & 5.3 & 0.02 \\
\hline EC039 & -4.52 & 35.4 & -5.41 & 575.0 & 1.41 & 6.1 & 0.52 \\
\hline MPI100 & -1.57 & 10.2 & 3.68 & 519.9 & -4.81 & 1.9 & 0.45 \\
\hline MPI052 & 5.05 & 11.9 & -5.15 & 756.6 & 9.40 & 1.6 & -0.80 \\
\hline MRI060 & -5.11 & 57.1 & $*-5.99$ & 2192.5 & 0.73 & 2.6 & -0.15 \\
\hline MRI020 & $*-7.12$ & 93.9 & $*-10.04$ & 4238.5 & 3.16 & 2.2 & 0.23 \\
\hline HG208 & -3.32 & 27.7 & 0.40 & 1062.5 & -4.65 & 2.6 & -0.93 \\
\hline HG093 & -4.67 & 105.4 & -4.45 & 4242.6 & -0.40 & 2.5 & -0.19 \\
\hline HG039 & -0.13 & 150.9 & -1.47 & 6409.1 & 1.44 & 2.4 & 0.11 \\
\hline NCM056 & $*-6.33$ & 213.6 & $*-5.08$ & 10108.6 & -1.37 & 2.1 & -0.12 \\
\hline NCM028 & $*-5.13$ & 274.6 & $*-2.29$ & 15982.6 & $*-2.91$ & 1.7 & -0.08 \\
\hline NCM14 & $*-6.16$ & 267.8 & ${ }^{*}-4.37$ & 16598.2 & -1.80 & 1.6 & -0.01 \\
\hline MME mean & $*-4.72$ & & $*-4.56$ & & 0.04 & & -0.20 \\
\hline MME median & $*-5.32$ & & ${ }^{*}-4.12$ & & 0.20 & & -1.40 \\
\hline
\end{tabular}

Fractional changes $(\Delta[\%])$ were calculated based on the ratio of differences between mean values of the future climate (2025-2049) and the present-day climate $(1990-2014)$ to the mean value of the present-day climate $\left(P_{\text {mean }}\right)$. In NCM014, we regard 2000-2009 as the present-day climate, and 2040-2049 as the future climate. Residual (Resi) was calculated based on Eq. 2. MME mean and median indicates change ratio of TC genesis frequency, TC seed frequency, and survival rate calculated from the multi models except NCM014, which were normalized based on the mean value from 1990 to 2014. Positive values indicate an increase in the respective variable due to global warming, whereas negative values denote a decrease. Statistical significance of future changes was determined with the Wilcoxon rank-sum test. An asterisk indicates that a future change is statistically significant at the $90 \%$ confidence level (at least)

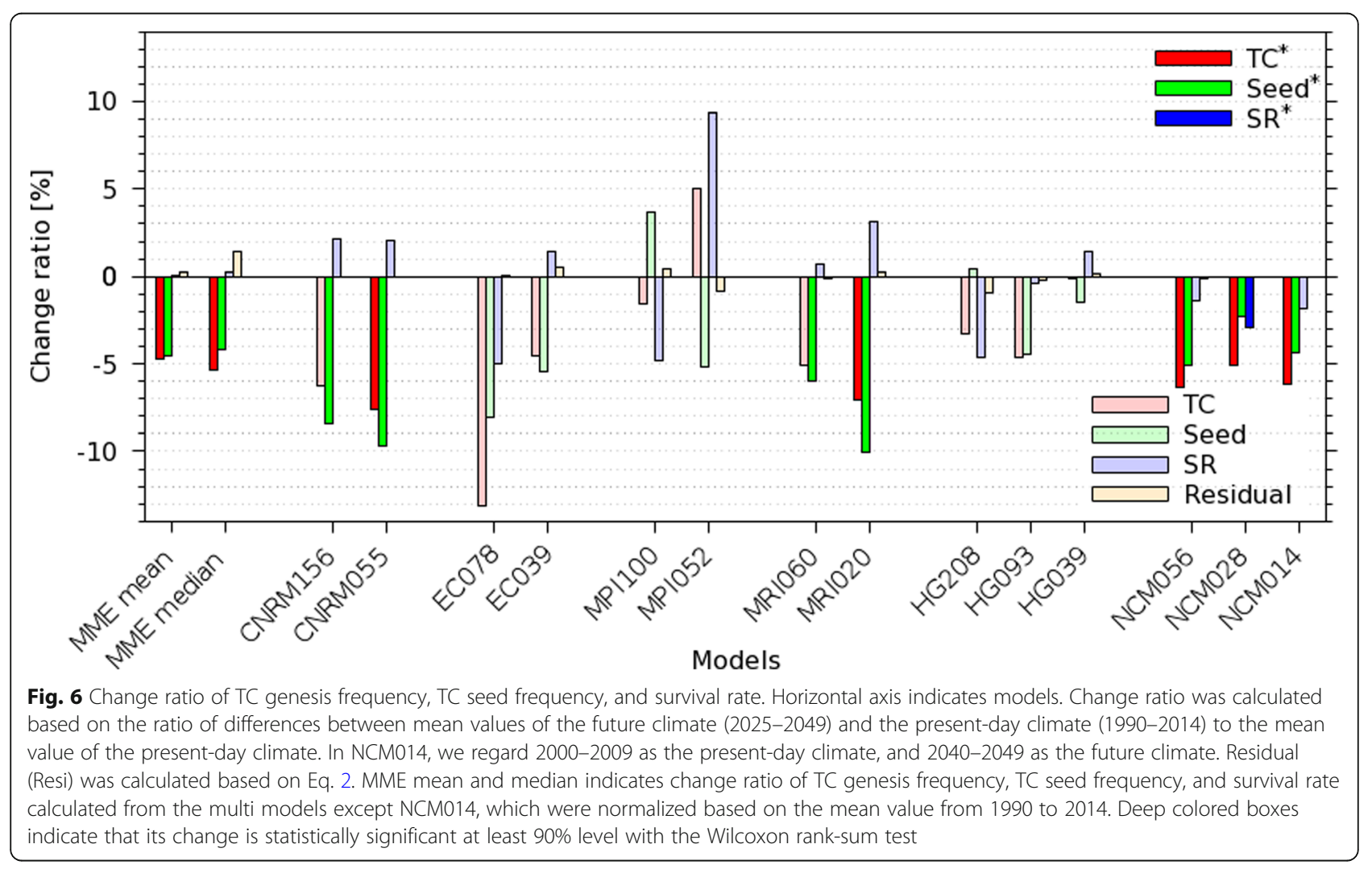


definition of the seed. Although the most models (12 models) showed a decrease in seed frequency, two lowresolution models (MPI100 and HG208) showed an increase. Inter-model differences in TC seed change might play a key role in understanding variability in future TC projections among models.

\subsection{Dependency on model and its resolution}

As seen in the previous subsection, our results showed little systematic change in the response of TC frequency, seed frequency, and SR to global warming in relation to horizontal resolution. This may be associated with the impact of horizontal resolution on the interannual variability of TC frequency, as shown in Roberts et al. (2019b). However, Roberts et al. (2019b) showed that $\mathrm{TC}$ frequency is substantially increased even for a single model with a reduced horizontal grid interval. Similarly, Fig. 1 and Table 6 show systematic increases in TC frequency for a single model with finer horizontal resolution. We discuss the dependencies of the three parameters on model type and horizontal resolution.

In Fig. 7, each panel shows the 25-year mean TC genesis frequency, seed frequency, and SR in the presentday climate (1990-2014), which are sorted by the horizontal resolution of each model. In NCM014, the period is from 2000 to 2009. The horizontal grid interval appears to be contributing to the difference in TC genesis frequency between resolutions for each model, but not to the difference between models (Fig. 7a). For instance, the higher-resolution version of EC-Earth3P (EC039) shows larger TC frequency than does its lowerresolution version (EC078). However, the TC genesis frequency of EC039 is less than those of HG093, MRI060, NCM056, and CNRM055, in which the horizontal grid intervals are larger than that of EC039.

A similar characteristic was seen in the TC seed frequency for inter-model differences and inter-horizontal resolutions for each model (Fig. 7b). On the other hand, the SR was higher in the lower-resolution versions of the models than it was in the higher-resolution versions (except for EC-Earth3P (Fig. 6c)). The three parameters linearly depended on the model's horizontal resolution. TC genesis frequency and TC seed frequency were increased with finer resolution for all the models, whereas SR showed a decreasing tendency (except for in ECEarth3P).

Summarizing Fig. 7, we can see the systematic increase in TC seeds for a single model with finer horizontal resolution. Models in which more seeds occur generate more TC. Inter-model differences in TC seeds might be related to model configuration, dynamical core, and physical process such as cumulus convection (Murakami et al. 2012; Reed et al. 2015; Zhao et al. 2012). For instance, Zhao et al. (2012) investigated the impact of damping of the divergent component of horizontal flow, showing a continuous increase in global TC frequency with increasing strength of the divergence damping.

\section{Summary and concluding remarks}

In the present study, we investigated future changes in TC seed frequency and its relation to TC frequency using a HighResMIP multi-model simulation. TempestExtremes was utilized for detecting TCs and TC seeds in each model. We estimated the SR, which defined the ratio of TC genesis frequency to TC seed frequency.

The MME showed a statistically significant decreasing trend in TC genesis frequency and TC seed frequency from 1990 to 2049. The SR did not show a significant trend. As for the individual models, models with a significant decreasing trend in TC frequency also showed significant decreasing trends in $\mathrm{TC}$ seed frequency (Table 3). Annual TC and seed frequency in the models and three reanalyses strongly correlated with each other (except for MPI-ESM1.2 and ERA-5) (Table 5). In addition, TC genesis frequency in IBTrACS was moderately correlated with the TC seeds detected in JRA- 55 (0.41). The correlation coefficients between annual TC frequency and SR were significant and were weaker than those between TC and seed frequencies, except for MPIESM1.2. The horizontal distributions of change in TC genesis frequency were similar to those in seed frequency for each model (Figs. 3 and 5). These results indicate that TC frequency is possibly constrained by TC seed, SR, and their balance. This is broadly consistent with the findings of Vecchi et al. (2019).

We compared the contributions of changes in TC seed frequency and SR to changes in TC genesis frequency between models and their horizontal resolutions (Fig. 6 and Table 6). In CNRM-CM6, MRI-AGCM3, and NICA M.16-S, the signs of the contributions of both parameters differed between models but were unchanged between horizontal resolutions. In CNRM-CM6 and MRIAGCM3, the decrease in TC seed overwhelmed the increase in SR, contributing to the decrease in TC frequency. In NICAM.16-S, the decreases in both factors contributed to the decrease in TC frequency. In ECEarth3P, MPI-ESM1.2, and HadGEM3-GC3.1, the signs of the contributions differed between not only the models but also their horizontal resolutions. These models did not show significant changes in TC frequency, seed frequency, and SR between the present-day and future climates (Fig. 6 and Table 6). Although the contributions of changes in TC seed and SR differed between models and their horizontal resolutions, the response of TC frequency to global warming is attributed to the response of TC seed and SR. These differences possibly induced the differences in the future projection of TC frequency across previous studies. Therefore, it is 


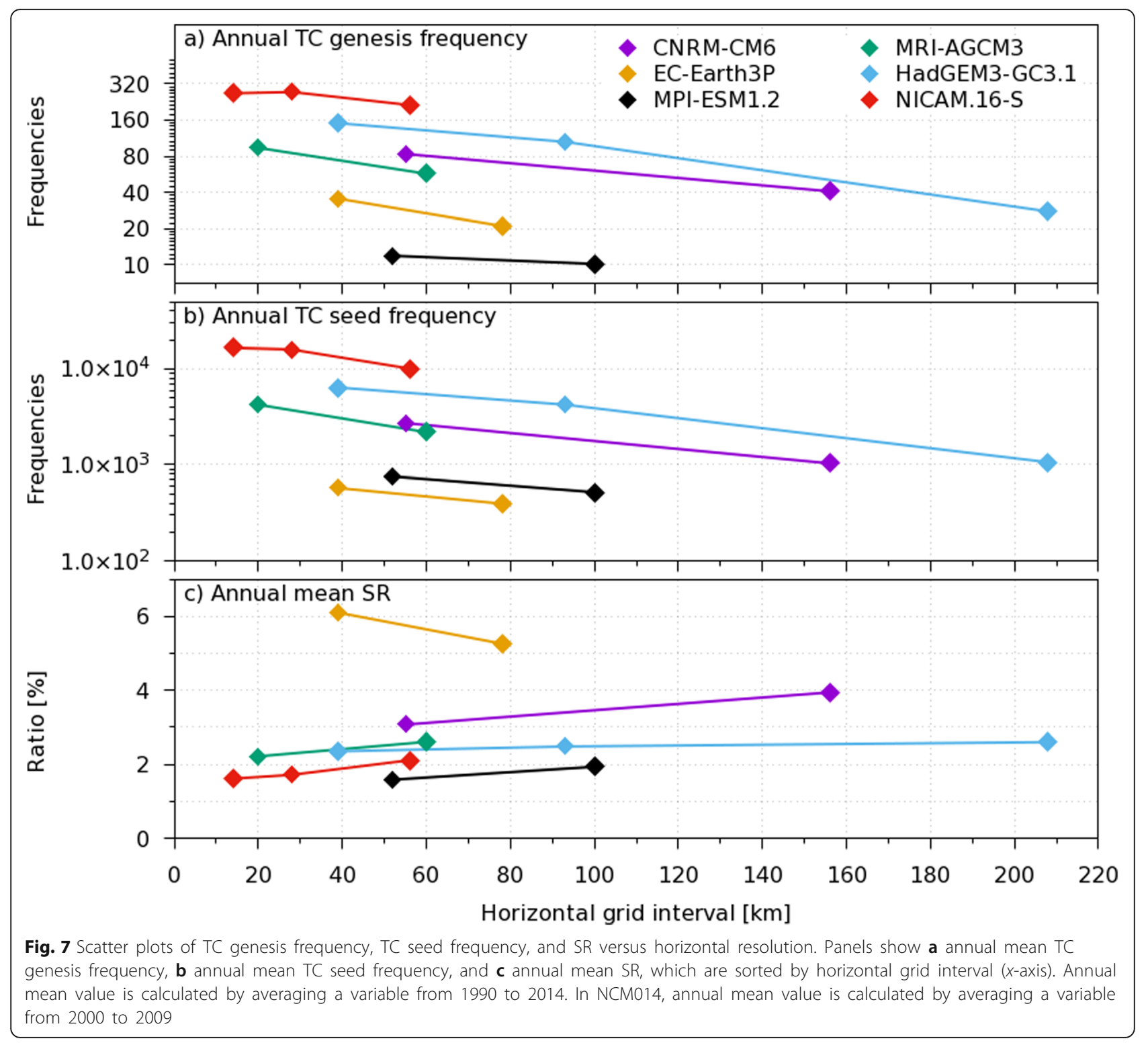

important to understand differences in the behavior of TC seeds in terms of climate change across models.

As well as the TC tracking algorithm and its criterion, the definition of $\mathrm{TC}$ seed is critical to elucidate the role of future TC seed changes in TC frequency change. Although the definition may be incomplete, a specific definition should be applied to all models to reduce complexity. In the present study, we simply defined candidates in the first step of TempestExtremes as TC seeds, i.e., disturbances having a closed contour of SLP with warm core (see Section 2.2). This definition may induce uncertainty of conclusion in the present study. We investigated the influence of (i) the geopotential requirement of third and fourth criteria in the first step of TempestExtremes, and (ii) duration of TC seed following
Tory et al. (2018). In the both cases, TC seed significantly correlates with TC genesis frequency even if the definition of TC seed is modified. However, these modifications affected the magnitude of contribution of TC seed and SR to future change in TC genesis frequency.

Recently, Camargo et al. (2020) demonstrated that the mean state of models does not have a consistent relationship with the mean TC activity in models by using thirty models, and suggested that understanding of TC seeds in addition to the large-scale environmental impact on $\mathrm{TC}$ genesis may provide information on understanding of model TC climatological biases. A more accurate definition is required to increase the robustness of the assessment of the impact of $\mathrm{TC}$ seed frequency on $\mathrm{TC}$ frequency. In 
addition, we did not discover any reason for why TC seed frequency changes with global warming, which might be related to the responses of the Madden-Julian Oscillation, easterly wave, and monsoon trough to global warming. These topics are candidates for future work.

\section{Supplementary Information}

The online version contains supplementary material available at https://doi. org/10.1186/s40645-020-00397-1

Additional file 1: Supplemental Figure 1. Horizontal distributions of annual TC genesis density. Panels show TC genesis densities of best track, reanalyses, and HighResMIP models: (a) IBTrACS, (b) ERA-I, (c) JRA-55, (d) ERA-5, (e) CNRM156, (f) CNRM055, (g) EC078, (h) EC039, (i) MPI100, (j) MPI052, (k) MRI060, (l) MRI020, (m) HG208, (n) HG093, (o) HG039, (p) NCM056, (q) NCM028, and (r) NCM014. Analysis periods are from 1990 to 2014 for panels $a-q$, and from 2000 to 2009 for panel $r$. The numbers in parentheses are the annual mean TC genesis frequencies during the respective analysis period for best track, reanalyses and each model. Genesis density was defined as the number of TCs per year generated in a $5^{\circ} \times 5^{\circ}$ grid box

Additional file 2: Supplemental Figure 2. Horizontal distributions of Normalized TC seed existence density. Panels show TC genesis densities of reanalyses and HighResMIP models: (a) ERA-l, (b) JRA-55, (c) ERA-5, (d) CNRM156, (e) CNRM055, (f) EC078, (g) EC039, (h) MPI100, (i) MPI052, (j) MRI060, (k) MRI020, (l) HG208, (m) HG093, (n) HG039, (o) NCM056, (p) NCM028, and (q) NCM014. Analysis periods are from 1990 to 2014 for panels $a-p$, and from 2000 to 2009 for panel q. The numbers in parentheses are the annual mean TC seed existence frequencies during the respective analysis period for reanalyses and each model. Existence density was defined as the number of TC seeds per year existed in a $5^{\circ} \times 5^{\circ}$ grid box. The existence densities are normalized by the respective annual mean TC seed existence frequency.

Additional file 3: Supplemental Figure 3. Horizontal distributions of Annual TC seed existence density. Panels show TC genesis densities of reanalyses and HighResMIP models: (a) ERA-l, (b) JRA-55, (c) ERA-5, (d) CNRM156, (e) CNRM055, (f) EC078, (g) EC039, (h) MPI100, (i) MPI052, (j) MRI060, (k) MRI020, (l) HG208, (m) HG093, (n) HG039, (o) NCM056, (p) NCM028, and (q) NCM014. Analysis periods are from 1990 to 2014 for panels $a-p$, and from 2000 to 2009 for panel q. The numbers in parentheses are the annual mean TC seed existence frequencies during the respective analysis period for reanalyses and each model. Existence density was defined as the number of TC seeds per year existed in a $5^{\circ} \times 5^{\circ}$ grid box.

\section{Additional file 4}

\section{Abbreviations}

CMIP6: The sixth phase of the Coupled Model Intercomparison Project; CNRM-CM6: Centre National de Recherches Meteorologiques and Cerfacs for CMIP6; CNRM055: CNRM-CM6 with a horizontal grid interval of $55 \mathrm{~km}$; CNRM156: CNRM-CM6 with a horizontal grid interval of $156 \mathrm{~km}$; EC039: ECEarth3P with a horizontal grid interval of 78 km; EC078: EC-Earth3P with a horizontal grid interval of 78 km; ECMWF: The European Centre for MediumRange Weather Forecasts; ERA-I: The ECMWF Interim Re-Analysis; ERA-5: The fifth-generation ECMWF reanalysis; HighResMIP: High Resolution Model Intercomparison Project; IBTrACS: International Best Track Archive for Climate Stewardship; JRA55: Japanese 55-year Reanalysis; MME: Multi model ensemble; MPI-ESM1.2: Max Planck Institute for Meteorology Earth System Model; MPI052: MPI-ESM1.2 with a horizontal grid interval of $52 \mathrm{~km}$; MPI100: MPI-ESM1.2 with a horizontal grid interval of $100 \mathrm{~km}$; MRIAGCM3: Meteorological Research Institute/Japan Meteorological Agency Atmospheric General Circulation Model; MRI020: MRI-AGCM3 with a horizontal grid interval of 20 km; MRI060: MRI-AGCM3 with a horizontal grid interval of 60 km; NICAM: Nonhydrostatic ICosahedral Atmospheric Model; NICAM.16-S: The latest stable version of NICAM modified for CMIP6; NCM014: NICAM with a horizontal grid interval of 14 km; NCM028: NICAM with a horizontal grid interval of $28 \mathrm{~km}$; NCM056: NICAM with a horizontal grid interval of 56 km; SLP: Sea level pressure; SR: Survival rate; SST: Sea surface temperature; TC: Tropical cyclone; TD: Tropical depression

\section{Acknowledgments}

JRA-55 data from the JMA, and ERA-5 and ERA-I data from the ECMWF. The HighResMIP simulations of NICAM.16-S and MRI-AGCM3 were performed on the Earth Simulator at the Japan Agency for Marine-Earth Science and Technology (JAMSTEC), and some of them on the K computer (proposal number hp150287, hp160230, hp170234, hp180182, and hp190152). The authors acknowledge Dr. Ishi and anonymous reviewers for their constructive comments, and Editorial office for their supports. We used Gnuplot and GrADS for drawing figures and python for statistical analysis. YY thanks Enago for the English language review.

\section{Authors' contributions}

YY analyzed the simulations and drafted the manuscript. CK, MSa, MSu, MJR, RM, ATN, TN, MN, and PLV helped in the interpretation and collaborated with the corresponding author in the construction of the manuscript. All coauthors participated in discussions of the results and commented on the original manuscript. MJR led CMIP6 HighResMIP and conducted HadGEM3GC3.1. CK conducted the simulations of NICAM.16-S. RM conducted the simulations of MRI-AGCM3. All authors read and approved the final manuscript.

\section{Funding}

This study was supported by the Environment Research and Technology Development Fund (2RF-1701) of the Environmental Restoration and Conservation Agency of Japan (ERCA); the Integrated Research Program for Advancing Climate Models (TOUGOU program: JPMXD0717935457, JPMXD0717935561), and the FLAGSHIP2020 project within the priority study4 (proposal number hp150287, hp160230, hp170234, hp180182, and hp190152), of the Ministry of Education, Culture, Sports, Science and Technology (MEXT) of Japan; and the PRIMAVERA project, funded by the European Union's Horizon 2020 program under Grant Agreement no. 641727.

\section{Availability of data and materials}

The HighResMIP datasets analyzed during the current study are (and will be) available in the Earth System Grid Federation repository, [https://esgf-node. Innl.gov/search/cmip6/]. Tropical cyclone tracks as calculated by the TempestExtremes algorithm are (and will be) available in the Centre for Environmental Data Analysis repository, [https://catalogue.ceda.ac.uk/uuid/43 8268b75fed4f27988dc02f8a1d756d].

\section{Competing interests}

The authors declare that they have no competing interests.

\section{Author details}

${ }^{1}$ Japan Agency for Marine-Earth Science and Technology, 3173-25 Showa-machi, Yokohama, Kanagawa 236-0001, Japan. ${ }^{2}$ Atmosphere and Ocean Research Institute, The University of Tokyo, 5-1-5 Kashiwanoha, Kashiwa, Chiba 277-8564, Japan. ${ }^{3}$ Meteorological Research Institute, Japan Meteorological Agency, 1-1 Nagamine, Tsukuba, Ibaraki 305-0052, Japan. ${ }^{4}$ Met Office, Exeter EX1 3PB, UK. ${ }^{5}$ National Centre for Atmospheric Science, Department of Meteorology, University of Reading, Reading RG6 6BB, UK.

Received: 31 March 2020 Accepted: 2 December 2020

Published online: 22 January 2021

\section{References}

Bhatia K, Vecchi G, Murakami H, Underwood S, Kossin J (2018) Projected response of tropical cyclone intensity and intensification in a global climate model. J Climate 31:8281-8303. https://doi.org/10.1175/JCLI-D-17-0898.1

Camargo SJ (2013) Global and regional aspects of tropical cyclone activity in the CMIP5 models. J Climate 26:9880-9902. https://doi.org/10.1175/JCLI-D-1200549.1

Camargo SJ, Giulivi CF, Sobel AH, Wing AA, Kim D, Moon Y, Strong JD, Del Genio $A D$, Kelley M, Murakami H, Reed KA, Scoccimarro E, Vecchi GA, Wehner MF, Zarzycki C, Zhao M (2020) Characteristics of model tropical cyclone climatology and the large-scale environment. J Climate 33:4463-4487. https://doi.org/10.1175/JCLI-D-19-0500.1 
Chu JH, Sampson CR, Levine AS, Fukada E, (2002) The joint typhoon warming center tropical cyclone best-tracks. NRL Tech. Rep. 1945-2000, NRL/MR/7540-02-16, http.// unw.usno.navy.mil/NOOC/nmfc-ph/RSS/jtwc/best_tracks/TC_bt_reporthtml.

Copernicus Climate Change Service (2017)ERA5: fifth generation of ECMWF atmospheric reanalyses of the global climate. Copernicus Climate Change Service Climate Data Store (CDS),

Dee DP, Uppala SM, Simmons AJ, Berrisford P, Poli P, Kobayashi S, Andrae U, Balmaseda MA, Balsamo G, Bauer P, Bechtold P, Beljaars ACM, van de Berg L, Bidlot J, Bormann N, Delsol C, Dragani R, Fuentes M, Geer AJ, Haimberger L, Healy SB, Hersbach $H$, Holm EV, Isaksen L, Kallberg P, Kohler M, Matricardi M, McNally AP, Monge-Sanz BM, Morcrette J-J, Park B-K, Peubey C, de Rosnay P, Tavolato C, Thepaut J-N, Vitart F (2011) The ERA-Interim reanalysis: configuration and performance of the data assimilation system. Q J Royal Meteorol Soc 137:553-597. https://doi.org/10.1002/qj.828

Eyring V, Bony S, Meehl GA, Senior C, Stevens B, Stouffer RJ, Taylor KE (2016) Overview of the coupled model intercomparison project phase 6 (CMIP6) experimental design and organization. Geosci Model Dev 9:1937-1958. https://doi.org/10.5194/gmd-9-1937-2016

Gutjahr O, Putrasahan D, Lohmann K, Jungclaus JH, von Storch JS, Brüggemann N, Haak H, Stössel A (2019) Max Planck Institute Earth System Model (MPI-ESM1.2) for the High-Resolution Model Intercomparison Project (HighResMIP). Geosci Model Dev 12:3241-3281. https://doi.org/10.5194/gmd-12-3241-2019

Haarsma R, Acosta M, Bakhshi R, Bretonnière PB, Caron LP, Castrillo M, Corti S, Davini P, Exarchou E, Fabiano F, Fladrich U, Fuentes Franco R, García-Serrano J, von Hardenberg J, Koenigk T, Levine X, Meccia V, van Noije T, van den Oord G, Palmeiro FM, Rodrigo M, Ruprich-Robert Y, Le Sager P, Tourigny É, Wang S, van Weele M, Wyser K (2020) HighResMIP versions of EC-Earth: EC-Earth3P and ECEarth3P-HR. Description, model performance, data handling and validation. Geosci Model Dev Discuss. https://doi.org/10.5194/gmd-2019-350

Haarsma RJ, Roberts MJ, Vidale PL, Senior CA, Bellucci A, Bao Q, Chang P, Corti S, Fuckar NS, Guemas V, von Hardenberg J, Hazeleger W, Kodama C, Koenigk T, Leung LR, Lu J, Luo JJ, Mao J, Mizielinski MS, Mizuta R, Nobre P, Satoh M, Scoccimarro E, Semmler T, Small J, von Storch JS (2016) High resolution model intercomparison project (HighResMIP v1.0) for CMIP6. Geosci Model Dev 9:4185-4208. https://doi.org/10.5194/gmd-9-4185-2016

Harada Y, Kamahori H, Kobayashi C, Endo H, Kobayashi S, Ota Y, Onoda H, Onogi K, Miyaoka K, Takahashi K (2016) The JRA-55 reanalysis: representation of atmospheric circulation and climate variability. J Meteorol Soc Japan 94:269302. https://doi.org/10.2151/jmsj.2016-015

Hodges K, Cobb A, Vidale PL (2017) How well are tropical cyclone represented in reanalysis datasets. J Climate 30:5243-5264. https:/doi.org/10.1175/JCL-D-16-0557.1

Hurley JV, Boo WR (2014) A global climatology of monsoon low-pressure systems. Q J Royal Meteorol Soc 141:1049-1064. https://doi.org/10.1002/qj.2447

Hussain MM, Mahmud I (2019) pyMannKendall: a python package for non parametric Mann Kendall family of trend tests. J Open Source Software 4 1556. https://doi.org/10.21105/joss.01556

Jarvinen BR, Neumann CJ, Davis MAS (1984) A tropical cyclone data tape for the North Atlantic basin, 1886-1983: contents, limitations, and uses. NOAA Tech. Memo NWS NHC 22:21. http://www.nhc.noaa.gov/pdf/NWSNHC-1988-22.pdf

Knapp KR, Diamond HJ, Kossin JP, Kruk MC, Schreck CJ (2018) International Best Track Archive for Climate Stewardship (IBTrACS) Project, Version 4. NOAA National Centers for Environmental Information. non-gonvernment domain. https://doi.org/10.25921/82ty-9e16. Accessed 30 Aug 2020.

Knapp KR, Kruk MC, Levinson DH, Diamond HJ, Neumann CJ (2010) The International Best Track Archive for Climate Stewardship (IBTrACS) Unifying tropical cyclone data. Bull Am Meteorol Soc 91:363-376. https://doi.org/10. 1175/2009BAMS2755.1

Knutson T, Camargo SJ, Chan JCL, Emanuel K, Ho C, Kossin J, Mohapatra M, Satoh M, Sugi M, Walsh K, Wu L (2019): Tropical cyclones and climate change assessment: Part I: detection and attribution. Bull Am Meteorol Soc 100 1987-2007. https://doi.org/10.1175/BAMS-D-18-0189.1

Kobayashi S, Ota Y, Harada Y, Ebita A, Moriya M, Onoda H, Onogi K, Kamahori H, Kobayashi C, Endo H, Miyaoka K, Takahashi K (2015) The JRA-55 reanalysis: general specifications and basic characteristics. J Meteorol Soc Japan 93:5-48. https://doi.org/10.2151/jmsj.2015-001

Kodama C, Ohno T, Seiki T, Yashiro H, Noda AT, Nakano M, Yamada Y, Woosub R, Satoh M, Nitta T, Goto D, Miura H, Nasuno T, Miyakawa T, Chen YW, Sugi M (2020) The non-hydrostatic global atmospheric model for CMIP6 HighResMIP simulations (NICAM16-S): Experimental design, model description, and sensitivity experiments. Geosci Model Dev Discuss. https://doi.org/10.5194/ gmd-2019-369 (Accepted)
Kodama C, Yamada Y, Noda AT, Kikuchi K, Kajikawa Y, Nasuno T, Tomita T, Yamaura T, Takahashi HG, Hara M, Kawatani Y, Satoh M, Sugi M (2015) A 20year climatology of a NICAM AMIP-Type simulation. J Meteorol Soc Japan 93: 393-424. https://doi.org/10.2151/jmsj.2015-024

Lee C-Y, Camargo SJ, Sobel AH, Tippett MK (2020) Statistical-dynamical downscaling projections of tropical cyclone activity in a warming climate: Two diverging genesis scenarios. J Climate 33:4815-4834. https://doi.org/10. 1175/JCLI-D-19-0452.1

Millman KJ, Aivazis M (2011) Python for Scientists and Engineers. Comput Sci Eng 13:9-12. https://doi.org/10.1109/MCSE.2011.36

Mizuta R, Adachi Y, Yukimoto S, Kusunoki S (2008) Estimation of the future distribution of sea surface temperature and sea ice using the CMIP3 multi-model ensemble mean. Tech Rep Meteorol Res Inst 56:28. https://doi.org/10.11483/mritechrepo.56

Mizuta R, Yoshimura H, Murakami H, Matsueda M, Endo H, Ose T, Kamiguchi K, Hosaka M, Sugi M, Yukimoto S, Kusunoki S, Kitoh A (2012) Climate simulations using MRI-AGCM3.2 with 20-km grid. J Meteorol Soc Japan 90A: 233-258. https://doi.org/10.2151/jmsj.2012-A12

Murakami H (2014) Tropical cyclone in reanalysis data sets. Geophys Res Lett 41: 2133-2141. https://doi.org/10.1002/2014GL059519

Murakami H, Hsu P, Arakawa O, Li T (2014) Influence of model biases on projected future changes in tropical cyclone frequency of occurrence. J Climate 27:2159-2181. https://doi.org/10.1175/JCLI-D-13-00436.1

Murakami $H$, Wang $Y$, Yoshimura H, Mizuta R, Sugi M, Shindo E, Adachi $Y$, Yukimoto S, Hosaka M, Kusunoki S, Ose T, Kitoh A (2012) Future changes in tropical cyclone activity projected by the new high-resolution MRI-AGCM. J Climate 25:3237-3260. https://doi.org/10.1175/JCLI-D-11-00415.1

Oliphant TE (2007) Python for Scientific Computing. Comput Sci Eng 9:10-20. https://doi.org/10.1109/MCSE.2007.58

Oouchi K, Yoshimura J, Yoshimura H, Mizuta R, Kusunoki S, Noda A (2006) Tropical cyclone climatology in a global warming climate as simulated in a $20 \mathrm{~km}$-mesh global atmospheric model: Frequency and wind intensity analysis. J Meteorol Soc Japan 84:259-276. https://doi.org/10.2151/jmsj.84.259

Reed KA, Bacmeister JT, Rosenbloom NA, Wehner MF, Bates SC, Lauritzen PH, Truesdale JE, Hannay C (2015) Impact of the dynamical core on the direct simulation of tropical cyclones in a high-resolution global model. Geophys Res Lett 42. https://doi.org/10.1002/2015GL063974

Roberts MJ (2019) CMIP6 HighResMIP: Tropical storm tracks as calculated by the TempestExtremes algorithm. Centre for Environmental Data Analysis. https:// catalogue.ceda.ac.uk/uuid/438268b75fed4f27988dc02f8a1d756d. Accessed 25 Feb 2019.

Roberts MJ, Baker A, Blockley EW, Calvert D, Coward A, Hewitt HT, Jackson LC, Kuhlbrodt $T$, Mathiot $P$, Roberts $C D$, Schiemann $R$, Seddon J, Vannière $B$, Vidale PL (2019a) Description of the resolution hierarchy of the global coupled HadGEM3-GC3.1 model as used in CMIP6 HighResMIP experiments. Geosci Model Dev 12:4999-5028. https://doi.org/10.5194/gmd-12-4999-2019

Roberts MJ, Camp J, Seddon J, Vidale PL, Hodges K, Vanniere B, Mecking J, Haarsma R, Bellucci A, Scoccimarro E, Caron LP, Chauvin F, Terray L, Valcke S, Moine MP, Putrasahan D, Roberts C, Senan R, Zarzycki C, Ullrich P (2019b) Impact of model resolution on tropical cyclone simulation using the HighResMIP-PRIMAVERA multi-model ensemble. J Climate 33:2557-2583. https://doi.org/10.1175/JCLI-D-19-0639.1

Roberts MJ, Camp J, Seddon J, Vidale PL, Hodges K, Vanniere B, Mecking J, Haarsma R, Bellucci A, Scoccimarro E, Caron LP, Chauvin F, Terray L, Valcke S, Moine MP, Putrasahan D, Roberts CD, Senan R, Zarzycki C, Ullrich P, Yamada Y, Mizuta R, Kodama C, Fu D, Zhang Q, Danabasoglu G, Rosenbloom N, Wang H, Wu L (2020) Projected future changes in tropical cyclones using the CMIP6 HighResMIP multi-model ensemble. Geophys Res Lett 47: e2020GL088662. https://doi.org/10.1029/2020GL088662

Roberts MJ, Vidale PL, Mizielinski MS, Strachan J, Hodges K, Bell R, Camp J (2015) Tropical cyclone in the UPSCALE ensemble of high resolution global climate models. J Climate 28:574-596. https://doi.org/10.1175/JCLI-D-14-00131.1

Satoh M, Matsuno T, Tomita H, Miura H, Nasuno T, Iga S (2008) Nonhydrostatic icosahedral atmospheric model (NICAM) for global cloud resolving simulations. J Comput Physics 227:3486-3514. https://doi.org/10.1016/j.jcp.2007.02.006

Satoh M, Tomita H, Yashiro H, Miura H, Kodama C, Seiki T, Noda AT, Yamada Y, Goto D, Sawada M, Miyoshi T, Niwa Y, Hara M, Ohno T, Iga S-I, Arakawa T, Inoue T, Kubokawa H (2014) The Non-hydrostatic Icosahedral Atmospheric Model: description and development. Prog Earth Planet Sci 1:18. https://doi.org/10.1186/s40645-014-0018-1

Satoh M, Yamada Y, Sugi M, Kodama C, Noda AT (2015) Constraint on future change in global frequency of tropical cyclones due to global warming. J Meteorol Soc Japan 93:489-500. https://doi.org/10.2151/jmsj.2015-025 
Sugi M, Murakami H, Yoshida K (2017) Projection of future changes in the frequency of intense tropical cyclones. Climate Dynamics 49:619-632. https:// doi.org/10.1007/s00382-016-3361-7

Sugi M, Murakami H, Yoshimura J (2009) A reduction in global tropical cyclone frequency due to global warming. Sci Online Lett Atmosphere 5:164-167. https://doi.org/10.2151/sola.2009-042

Sugi M, Yamada Y, Yoshida K, Mizuta R, Nakano M, Kodama C, Satoh M (2020) Future changes in the global frequency of tropical cyclone seeds. Sci Online Lett Atmosphere (in press)

Sugi M, Yoshimura J (2012) Decreasing trend of tropical cyclone frequency in 228-year high-resolution AGCM simulations. Geophys Res Lett. 39:L19805. https://doi.org/10.1029/2012GL053360

Thomas R. Knutson, John L. McBride, Johnny Chan, Kerry Emanuel, Greg Holland, Chris Landsea, Isaac Held, James P. Kossin, A. K. Srivastava, Masato Sugi, (2010) Tropical cyclones and climate change. Nature Geoscience 3 (3):157163

Thomas Knutson, Suzana J. Camargo, Johnny C. L. Chan, Kerry Emanuel, ChangHoi Ho, James Kossin, Mrutyunjay Mohapatra, Masaki Satoh, Masato Sugi, Kevin Walsh, Liguang Wu, (2020) Tropical Cyclones and Climate Change Assessment: Part II: Projected Response to Anthropogenic Warming. Bulletin of the American Meteorological Society 101 (3):E303-E322

Titchner HA, Rayner NA (2014) The Met Office Hadley Centre sea ice and sea surface temperature data set, version 2: 1. Sea ice concentrations. J Geophys Res Atmosphere 119:2864-2889. https://doi.org/10.1002/2013JD020316

Tomita H, Satoh M (2004) A new dynamical framework of nonhydrostatic global model using the icosahedral grid. Fluid Dynamics Res 34:357-400. https:// doi.org/10.1016/j.fluiddyn.2004.03.003

Tory KJ, Chand SS, Dare RA, McBride JL (2013a) The development and assessment of a model-, grid-, and basin-independent tropical cyclone detection scheme. J Climate 26:5493-5507. https://doi.org/10.1175/JCLI-D-12-00510.1

Tory KJ, Ye H, Chand SS, Dare RA, McBride JL (2013b) An assessment of a model-, grid-, and basin-independent tropical cyclone detection scheme in selected CMIP3 global climate models. J Climate 26:5508-5522. https://doi.org/10. 1175/JCLI-D-12-0511.1

Tory KJ, Ye H, Dare RA (2018) Understanding the geographic distribution of tropical cyclone formation for applications in climate models. Climate Dynamics 50:2489-2512. https://doi.org/10.1007/s00382-017-3752-4

Ullrich PA, Zarzycki CM (2017) TempestExtremes: a framework for scale-insensitive pointwise feature tracking on unstructured grids. Geosci Model Dev 10:10691090. https://doi.org/10.5194/gmd-10-1069-2017

Vecchi GA, Delworth TL, Murakami H, Underwood SD, Wittenberg AT, Zeng F, Zhang W, Baldwin JW, Bhatia KT, Cooke W, He J, Kapnick SB, Knutson TR, Villarini G, van der Wiel K, Anderson W, Balaji V, Chen JH, Dixon KW, Gudgel R, Harris LM, Jia L, Johnson NC, Lin SJ, Liu M, Ng CHJ, Rosati A, Smith JA, Yang X (2019) Tropical cyclone sensitivities to CO2 doubling: roles of atmospheric resolution, synoptic variability and background climate changes. Climate Dynamics 53:5999-6033. https://doi.org/10.1007/s00382-019-04913-y

Voldoire A, Saint-Martin D, Sénési S, Decharme B, Alias A, Chevallier M, Colin J, Guérémy JF, Michou M, Moine MP, Nabat P, Roehrig R, Salas y Mélia D, Séférian R, Valcke S, Beau I, Belamari S, Berthet S, Cassou C, Cattiaux J, Deshayes J, Douville H, Ethé C, Franchistéguy L, Geoffroy O, Lévy C, Madec G, Meurdesoif Y, Msadek R, Ribes A, Sanchez-Gomez E, Terray L, Waldman R (2019) Evaluation of CMIP6 DECK experiments with CNRM-CM6-1. J Adv Model Earth Syst, 11:2177-2213. https://doi.org/10.1029/2019MS001683

Wehner M, Prabhat RKA, Stone D, Collins WD, Bacmeister J (2015) Resolution dependence of future tropical cyclone projections of CAM5.1 in the US CLIV AR Hurricane Working Group idealized configurations. J Climate 28:39053925. https://doi.org/10.1175/JCLI-D-14-00311.1

Yamada Y, Oouchi K, Satoh M, Tomita H, Yanase W (2010) Projection of changes in tropical cyclone activity and cloud height due to greenhouse warming: global cloud-system-resolving approach. Geophys Res Lett 37. https://doi. org/10.1029/2010GL042518

Yamada Y, Satoh M (2013) Response of ice and liquid water paths of tropical cyclones to global warming simulated by a global nonhydrostatic model with explicit cloud microphysics. J Climate 26:9931-9945. https://doi.org/10. 1175/JCLI-D-13-00182.1

Yamada Y, Satoh M, Sugi M, Kodama C, Noda AT, Nakano M, Nasuno T (2017) Response of tropical cyclone activity and structure to global warming in a high-resolution global nonhydrostatic model. 30:9703-9724, doi:https://doi. org/10.1175/JCLI-D-17-0068.1
Yoshida K, Sugi M, Mizuta R, Murakami H, Ishii M (2017) Future changes in tropical cyclone activity in high-resolution large-ensemble simulations. Geophys Res Lett 44:9910-9917. https://doi.org/10.1002/2017/GL07058

Zarzycki CM, Ullrich PA (2017) Assessing sensitivities in algorithmic detection of tropical cyclones in climate data. Geophysical Research Letters 44:1141-1149. https://doi.org/10.1002/2016GL071606

Zhao M, Held IM, Lin S-J (2012) Some counterintuitive dependencies of tropical cyclone frequency on parameters in a GCM. J Atmospheric Sci 69:2272-2283. https://doi.org/10.1175/JAS-D-11-0238.1

Zhao M, Held IM, Lin SJ, Vecchi GA (2009) Simulations of global hurricane climatology, interannual variability, and response to global warming using a 50-km resolution GCM. Journal of Climate 22:6653-6678. https://doi.org/10. 1175/2009JCLI3049.1

\section{Publisher's Note}

Springer Nature remains neutral with regard to jurisdictional claims in published maps and institutional affiliations.

\section{Submit your manuscript to a SpringerOpen ${ }^{\circ}$ journal and benefit from:}

- Convenient online submission

- Rigorous peer review

- Open access: articles freely available online

High visibility within the field

- Retaining the copyright to your article

Submit your next manuscript at $\boldsymbol{\sim}$ springeropen.com 